\title{
Primary immunodeficiency diseases: an update on the classification from the International Union of Immunological Societies Expert Committee for Primary Immunodeficiency
}

\section{Waleed Al-Herz ${ }^{1,2}$, Aziz Bousfiha ${ }^{3}$, Jean-Laurent Casanova ${ }^{4,5}$, Helen Chapel $^{6}$, Mary Ellen Conley ${ }^{7,8 *}$, Charlotte Cunningham-Rundles ${ }^{9}$, Amos Etzioni $^{10}$, Alain Fischer ${ }^{11}$, Jose Luis Franco ${ }^{12}$, Raif S. Geha ${ }^{13}$, Lennart Hammarström ${ }^{14}$, Shigeaki Nonoyama ${ }^{15}$, Luigi Daniele Notarangelo ${ }^{13,16 *}{ }^{2}$, Hans Dieter Ochs ${ }^{17}$, Jennifer M. Puck ${ }^{18}$, Chaim M. Roifman ${ }^{19}$, Reinhard Seger ${ }^{20}$ and Mimi L. K. Tang ${ }^{21,22,23}$}

${ }^{1}$ Department of Pediatrics, Kuwait University, Kuwait City, Kuwait

2 Allergy and Clinical Immunology Unit, Department of Pediatrics, Al-Sabah Hospital, Kuwait City, Kuwait

${ }^{3}$ Clinical Immunology Unit, Casablanca Children Hospital Ibn Rochd Medical School, King Hassan II University, Casablanca, Morocco

${ }^{4}$ St. Giles Laboratory of Human Genetics of Infectious Diseases, Rockefeller Branch, The Rockefeller University, New York, NY, USA

${ }^{5}$ Laboratory of Human Genetics of Infectious Diseases, Necker Branch, Necker Medical School, University Paris Descartes and INSERM U980, Paris, France

${ }^{6}$ Clinical Immunology Unit, Nuffield Department of Medicine, University of Oxford, Oxford, UK

7 Department of Pediatrics, University of Tennessee College of Medicine, Memphis, TN, USA

${ }^{8}$ Department of Immunology, St. Jude Children's Research Hospital, Memphis, TN, USA

${ }^{9}$ Department of Medicine and Pediatrics, Mount Sinai School of Medicine, New York, NY, USA

${ }_{10}$ Meyer's Children Hospital - Technion, Haifa, Israel

"Pediatric Hematology-Immunology Unit, Hôpital Necker Enfants-Malades, Assistance Publique-Hôpital de Paris, Necker Medical School, Paris Descartes University, Paris, France

12 Group of Primary Immunodeficiencies, University of Antioquia, Medellín, Colombia

${ }_{13}^{13}$ Division of Immunology, Children's Hospital Boston, Boston, MA, USA

${ }^{14}$ Division of Clinical Immunology, Department of Laboratory Medicine, Karolinska Institute at Karolinska University Hospital Huddinge, Stockholm, Sweden

${ }^{15}$ Department of Pediatrics, National Defense Medical College, Saitama, Japan

${ }_{16}$ The Manton Center for Orphan Disease Research, Children's Hospital Boston, Boston, MA, USA

17 Department of Pediatrics, University of Washington and Seattle Children's Research Institute, Seattle, WA, USA

${ }_{18}$ Department of Pediatrics, University of California San Francisco and UCSF Benioff Children's Hospital, San Francisco, CA, USA

${ }^{19}$ Division of Immunology and Allergy, Department of Pediatrics, The Hospital for Sick Children and the University of Toronto, Toronto, ON, Canada

${ }^{20}$ Division of Immunology, University Children's Hospital, Zürich, Switzerland

${ }^{21}$ Department of Allergy and Immunology, Royal Children's Hospital Melbourne, Melbourne, VIC, Australia

${ }^{22}$ Murdoch Childrens Research Institute, Melbourne, Melbourne, VIC, Australia

${ }^{23}$ Department of Paediatrics, University of Melbourne, Melbourne, VIC, Australia

\section{Edited by:}

Eric Meffre, Yale University School of Medicine, USA

\section{Reviewed by:}

Eric Meffre, Yale University School of Medicine, USA

\section{*Correspondence:}

Mary Ellen Conley, Department of Pediatrics, University of Tennessee College of Medicine, Memphis, TN USA; Department of Immunology MS 351, St. Jude Children's Research Hospital, 262 Danny Thomas Place, Memphis, TN 38105, USA.

e-mail:maryellen.conley@stjude.org;

Luigi Daniele Notarangelo, Division of Immunology and The Manton Center for Orphan Disease Research, Children's Hospital Boston, Karp Research Building, Room 20217, 1 Blackfan Circle, Boston, MA 02115, USA.

e-mail: luigi.notarangelo@childrens. harvard.edu
We report the updated classification of primary immunodeficiency diseases, compiled by the ad hoc Expert Committee of the International Union of Immunological Societies. As compared to the previous edition, more than 15 novel disease entities have been added in the updated version. For each disorders, the key clinical and laboratory features are provided. This updated classification is meant to help in the diagnostic approach to patients with these diseases.

Keywords: primary immunodeficiency diseases 
The International Union of Immunological Societies (IUIS) Expert Committee on Primary Immunodeficiency met in New York City, May 31-June 1, 2011 to update the classification of human primary immunodeficiencies (PIDs). Novel developments in gene discovery and increased knowledge in the mechanisms that govern immune system development and function have resulted in the identification of several novel PIDs in the last 2 years.

The classification of primary immunodeficiencies (PIDs) provides a framework to help in the diagnostic approach to patients. As in recent classifications, eight major groups of PIDs have been included in the Tables; however the order of the Tables has been changed with Table 2 now describing the "Well-defined syndromes with immunodeficiency" (previously Table 3 ) to reflect the immunological similarity between the disorders included in this Table and those in Table 1, "Combined immunodeficiencies."

Any classification of human disorders is somewhat arbitrary, and the classification of PIDs is no exception. Some disorders might well belong to more than one group. CD40 ligand deficiency, for example, is reported both in Tables $\mathbf{1}$ and $\mathbf{3}$ ("Predominantly antibody deficiencies"), to reflect the facts that failed B cell isotype switching was historically the most prominent feature of this condition (originally named Hyper-IgM syndrome) and that some patients survive into adulthood without significant opportunistic infections and do well with only immunoglobulin replacement therapy. Explanatory notes provided after each Table offer additional information (particularly where a condition appears in more than one Table) and indicate which new disorders have been added to that Table.

Although this updated classification reports on the most typical immunological findings and associated clinical and genetic features for the various PIDs, there is extensive clinical, immunological, and molecular heterogeneity that can not be easily recapitulated in a brief summary. To facilitate a more rigorous analysis of each disease, a column has been added on the right with a hyperlink to refer to its catalog number in the Online Mendelian Inheritance in Man (OMIM) publicly accessible database (www.omim.org) of human genetic disorders. It is suggested that the reader consult this regularly updated and fully referenced resource.

The prevalence of the various PIDs varies in different countries. For this reason, in this new classification, we have elected to avoid giving a comment on the relative frequency of PID disorders. However, an asterisk has been placed in the first column, after the disease name, to identify disorders for which fewer than 10 unrelated cases have been reported in the literature. Some of these forms of PID can be considered extremely rare. Others have only recently been identified and it may be that more patients will be detected over time.

Finally, it is increasingly recognized that different mutations in the same gene may result in different phenotypes and may be associated with different patterns of inheritance. This concept of clinical, immunological, and genetic heterogeneity is assuming foremost importance. Notes in the text or in the footnotes identify such heterogeneity, when known.

The scope of the IUIS Expert Committee on Primary Immunodeficiency is to increase awareness, facilitate recognition, and promote optimal treatment for patients with Primary Immunodeficiency disorders worldwide. For this reason, in addition to periodically revising the Classification of PIDs, the Expert Committee is also actively involved in the development of diagnostic criteria and in providing, upon request, advice with regard to therapeutic guidelines. 
Table 1 | Combined immunodeficiencies.

\begin{tabular}{lllll}
\hline Disease & Circulating & Circulating & Serum Ig & $\begin{array}{l}\text { Associated } \\
\text { features }\end{array}$
\end{tabular}

$\begin{array}{ll}\text { Inheri- } & \begin{array}{l}\text { Genetic defect/ } \\ \text { presumed } \\ \text { pathogenesis }\end{array}\end{array}$

\section{1. $T^{-} B^{+}$Severe combined immunodeficiency (SCID)}

\begin{tabular}{|c|c|c|c|}
\hline $\begin{array}{l}\text { (a) } \gamma c \\
\text { deficiency }\end{array}$ & $\begin{array}{l}\text { Markedly } \\
\text { decreased }\end{array}$ & $\begin{array}{l}\text { Normal or } \\
\text { increased }\end{array}$ & Decreased \\
\hline
\end{tabular}

Markedly decreased NK cells; $\quad X$ leaky cases may present with low to normal T and/or NK cells or Omenn syndrome

\begin{tabular}{|c|c|c|c|c|c|c|c|}
\hline $\begin{array}{l}\text { (b) JAK3 } \\
\text { deficiency }\end{array}$ & $\begin{array}{l}\text { Markedly } \\
\text { decreased }\end{array}$ & $\begin{array}{l}\text { Normal or } \\
\text { increased }\end{array}$ & Decreased & $\begin{array}{l}\text { Markedly decreased NK cells; } \\
\text { leaky cases may present with } \\
\text { variable T and/or NK cells }\end{array}$ & $A R$ & $\begin{array}{l}\text { Defect in Janus activating } \\
\text { kinase } 3\end{array}$ & 600173 \\
\hline $\begin{array}{l}\text { (c) IL7R } \alpha \\
\text { deficiency }\end{array}$ & $\begin{array}{l}\text { Markedly } \\
\text { decreased }\end{array}$ & $\begin{array}{l}\text { Normal or } \\
\text { increased }\end{array}$ & Decreased & Normal NK cells & $A R$ & Defect in IL-7 receptor $\alpha$ chain & 146661 \\
\hline $\begin{array}{l}\text { (d) CD45 } \\
\text { deficiency* }\end{array}$ & $\begin{array}{l}\text { Markedly } \\
\text { decreased }\end{array}$ & Normal & Decreased & Normal $\gamma / \delta T$ cells & $A R$ & Defect in CD45 & 151460 \\
\hline $\begin{array}{l}\text { (e) } \operatorname{CD} 3 \delta^{*} / \\
\mathrm{CD}^{*} \varepsilon^{*} / \mathrm{CD} 3 \zeta^{*} \\
\text { deficiency }\end{array}$ & $\begin{array}{l}\text { Markedly } \\
\text { decreased }\end{array}$ & Normal & Decreased & $\begin{array}{l}\text { Normal NK cells } \\
\text { No } \gamma / \delta T \text { cells }\end{array}$ & AR & $\begin{array}{l}\text { Defect in } \mathrm{CD} 3 \delta, \mathrm{CD} 3 \varepsilon \text {, or } \\
\mathrm{CD} 3 \zeta \text { chains of } \mathrm{T} \text { cell antigen } \\
\text { receptor complex }\end{array}$ & $\begin{array}{l}186790 \\
186830 \\
186740\end{array}$ \\
\hline $\begin{array}{l}\text { (f) Coronin-1A } \\
\text { deficiency* }^{*}\end{array}$ & $\begin{array}{l}\text { Markedly } \\
\text { decreased }\end{array}$ & Normal & Decreased & Detectable thymus & $A R$ & $\begin{array}{l}\text { Defective thymic egress of } \mathrm{T} \\
\text { cells and defective } \mathrm{T} \text { cell } \\
\text { locomotion }\end{array}$ & 605000 \\
\hline $\begin{array}{l}\text { 2. } \mathbf{T}^{-} \mathbf{B}^{-} \text {SCID } \\
\text { (a) RAG } 1 / 2 \\
\text { deficiency }\end{array}$ & $\begin{array}{l}\text { Markedly } \\
\text { decreased }\end{array}$ & $\begin{array}{l}\text { Markedly } \\
\text { decreased }\end{array}$ & Decreased & $\begin{array}{l}\text { May present with Omenn } \\
\text { syndrome, expanded } \gamma / \delta T \\
\text { cells, autoimmunity, and/or } \\
\text { granulomas }\end{array}$ & AR & $\begin{array}{l}\text { Defective VDJ recombination; } \\
\text { defect of recombinase } \\
\text { activating gene (RAG) } 1 \text { or } 2\end{array}$ & 601457 \\
\hline $\begin{array}{l}\text { (b) DCLRE1C } \\
\text { (Artemis) } \\
\text { deficiency }\end{array}$ & $\begin{array}{l}\text { Markedly } \\
\text { decreased }\end{array}$ & $\begin{array}{l}\text { Markedly } \\
\text { decreased }\end{array}$ & Decreased & $\begin{array}{l}\text { Defective VDJ recombination, } \\
\text { radiation sensitivity; may } \\
\text { present with Omenn } \\
\text { syndrome }\end{array}$ & AR & $\begin{array}{l}\text { Defective VDJ recombination; } \\
\text { defect in Artemis DNA } \\
\text { recombinase repair protein }\end{array}$ & 602450 \\
\hline $\begin{array}{l}\text { (c) DNA-PKcs } \\
\text { deficiency* }\end{array}$ & $\begin{array}{l}\text { Markedly } \\
\text { decreased }\end{array}$ & $\begin{array}{l}\text { Markedly } \\
\text { decreased }\end{array}$ & Decreased & $\begin{array}{l}\text { (Widely studied scid mouse } \\
\text { defect) }\end{array}$ & $A R$ & $\begin{array}{l}\text { Defective VDJ recombination; } \\
\text { defect in DNA-PKcs } \\
\text { recombinase repair protein }\end{array}$ & 600899 \\
\hline $\begin{array}{l}\text { (d) Reticular } \\
\text { dysgenesis, } \\
\text { AK2 } \\
\text { deficiency }\end{array}$ & $\begin{array}{l}\text { Markedly } \\
\text { decreased }\end{array}$ & $\begin{array}{l}\text { Decreased or } \\
\text { normal }\end{array}$ & Decreased & $\begin{array}{l}\text { Deficiency of T, B, and NK } \\
\text { cells with granulocytopenia, } \\
\text { deafness }\end{array}$ & AR & $\begin{array}{l}\text { Defective maturation of } \\
\text { lymphoid and myeloid cells } \\
\text { (stem cell defect) defect in } \\
\text { mitochondrial adenylate } \\
\text { kinase } 2\end{array}$ & 103020 \\
\hline $\begin{array}{l}\text { (e) Adenosine } \\
\text { deaminase } \\
\text { (ADA) } \\
\text { deficiency }\end{array}$ & $\begin{array}{l}\text { Absent from } \\
\text { birth (null } \\
\text { mutations) or } \\
\text { progressive } \\
\text { decrease }\end{array}$ & $\begin{array}{l}\text { Absent from } \\
\text { birth of } \\
\text { progressive } \\
\text { decrease }\end{array}$ & $\begin{array}{l}\text { Progressive } \\
\text { decrease }\end{array}$ & $\begin{array}{l}\text { Decreased NK cells, often } \\
\text { with costochondral junction } \\
\text { flaring, neurological features, } \\
\text { hearing impairment, lung, and } \\
\text { liver manifestations; partial } \\
\text { ADA deficiency may lead to } \\
\text { delayed or milder } \\
\text { presentation }\end{array}$ & AR & $\begin{array}{l}\text { Absent ADA activity, elevated } \\
\text { lymphotoxic metabolites } \\
\text { (dATP, } \\
\text { S-adenosylhomocysteine) }\end{array}$ & 102700 \\
\hline
\end{tabular}

Defect in $\gamma$ chain of receptors 300400 for IL-2, $-4,-7,-9,-15,-21$

OMIM

number

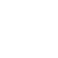


Table 1 | Continued

\begin{tabular}{|c|c|c|c|c|c|c|c|}
\hline Disease & $\begin{array}{l}\text { Circulating } \\
\text { T cells }\end{array}$ & $\begin{array}{l}\text { Circulating } \\
\text { B cells }\end{array}$ & Serum Ig & $\begin{array}{l}\text { Associated } \\
\text { features }\end{array}$ & $\begin{array}{l}\text { Inheri- } \\
\text { tance }\end{array}$ & $\begin{array}{l}\text { Genetic defect/ } \\
\text { presumed } \\
\text { pathogenesis }\end{array}$ & $\begin{array}{l}\text { OMIM } \\
\text { number }\end{array}$ \\
\hline $\begin{array}{l}\text { 3. Omenn } \\
\text { syndrome }\end{array}$ & $\begin{array}{l}\text { Present; } \\
\text { restricted } \\
\text { heterogene- } \\
\text { ity }\end{array}$ & $\begin{array}{l}\text { Normal or } \\
\text { decreased }\end{array}$ & $\begin{array}{l}\text { Decreased, } \\
\text { except } \\
\text { increased } \\
\lg E\end{array}$ & $\begin{array}{l}\text { Erythroderma, eosinophilia, } \\
\text { adenopathies, } \\
\text { hepatosplenomegaly }\end{array}$ & AR & $\begin{array}{l}\text { Hypomorphic mutations in } \\
\text { RAG1/2, Artemis, IL7R } \alpha \text {, } \\
\text { RMRP, ADA, DNA Ligase IV, } \\
\gamma \text { c, or associated with } \\
\text { DiGeorge syndrome; some } \\
\text { cases have no defined gene } \\
\text { mutation }\end{array}$ & 603554 \\
\hline $\begin{array}{l}\text { 4. DNA ligase } \\
\text { IV deficiency }\end{array}$ & Decreased & Decreased & Decreased & $\begin{array}{l}\text { Microcephaly, facial } \\
\text { dysmorphisms, radiation } \\
\text { sensitivity; may present with } \\
\text { Omenn syndrome or with a } \\
\text { delayed clinical onset }\end{array}$ & AR & $\begin{array}{l}\text { DNA ligase IV defect, } \\
\text { impaired non-homologous } \\
\text { end joining (NHEJ) }\end{array}$ & 601837 \\
\hline $\begin{array}{l}\text { 5. Cernunnos/ } \\
\text { NHEJ1 } \\
\text { deficiency* }\end{array}$ & Decreased & Decreased & Decreased & $\begin{array}{l}\text { Microcephaly, in utero growth } \\
\text { retardation, radiation } \\
\text { sensitivity }\end{array}$ & $A R$ & $\begin{array}{l}\text { Cernunnos (NHEJ1) defect, } \\
\text { impaired non-homologous } \\
\text { end joining }\end{array}$ & 611291 \\
\hline $\begin{array}{l}\text { 6. CD40 } \\
\text { ligand } \\
\text { deficiency }\end{array}$ & $\begin{array}{l}\text { Normal; may } \\
\text { progressively } \\
\text { decrease }\end{array}$ & $\begin{array}{l}\lg M^{+} \text {and } \\
\lg D^{+} \mathrm{B} \text { cells } \\
\text { present, } \\
\text { other } \\
\text { isotypes } \\
\text { absent }\end{array}$ & $\begin{array}{l}\text { IgM } \\
\text { increased } \\
\text { or normal, } \\
\text { other } \\
\text { isotypes } \\
\text { decreased }\end{array}$ & $\begin{array}{l}\text { Neutropenia, } \\
\text { thrombocytopenia; hemolytic } \\
\text { anemia, biliary tract, and liver } \\
\text { disease, opportunistic } \\
\text { infections }\end{array}$ & $X \mathrm{~L}$ & $\begin{array}{l}\text { Defects in CD40 ligand } \\
\text { (CD40L) cause defective } \\
\text { isotype switching and } \\
\text { impaired dendritic cell } \\
\text { signaling }\end{array}$ & 300386 \\
\hline $\begin{array}{l}\text { 7. CD40 } \\
\text { deficiency* }\end{array}$ & Normal & $\begin{array}{l}\operatorname{lgM}^{+} \text {and } \\
\lg D^{+} \mathrm{B} \text { cells } \\
\text { present, } \\
\text { other } \\
\text { isotypes } \\
\text { absent }\end{array}$ & $\begin{array}{l}\text { IgM } \\
\text { increased } \\
\text { or normal, } \\
\text { other } \\
\text { isotypes } \\
\text { decreased }\end{array}$ & $\begin{array}{l}\text { Neutropenia, gastrointestinal, } \\
\text { and liver/biliary tract disease, } \\
\text { opportunistic infections }\end{array}$ & $A R$ & $\begin{array}{l}\text { Defects in CD40 cause } \\
\text { defective isotype switching } \\
\text { and impaired dendritic cell } \\
\text { signaling }\end{array}$ & 109535 \\
\hline $\begin{array}{l}\text { 8. Purine } \\
\text { nucleoside } \\
\text { phosphory- } \\
\text { lase (PNP) } \\
\text { deficiency }\end{array}$ & $\begin{array}{l}\text { Progressive } \\
\text { decrease }\end{array}$ & Normal & $\begin{array}{l}\text { Normal or } \\
\text { decreased }\end{array}$ & $\begin{array}{l}\text { Autoimmune hemolytic } \\
\text { anemia, neurological } \\
\text { impairment }\end{array}$ & $A R$ & $\begin{array}{l}\text { Absent PNP, T cell and } \\
\text { neurologic defects from } \\
\text { elevated toxic metabolites, } \\
\text { especially dGTP }\end{array}$ & 164050 \\
\hline $\begin{array}{l}\text { 9. } \operatorname{CD} 3 \gamma \\
\text { deficiency* }\end{array}$ & $\begin{array}{l}\text { Normal, but } \\
\text { reduced TCR } \\
\text { expression }\end{array}$ & Normal & Normal & & AR & Defect in CD3 $\gamma$ & 186740 \\
\hline $\begin{array}{l}\text { 10. CD8 } \\
\text { deficiency* }\end{array}$ & $\begin{array}{l}\text { Absent CD8, } \\
\text { normal CD4 } \\
\text { cells }\end{array}$ & Normal & Normal & & $A R$ & Defects of CD8 $\alpha$ chain & 186910 \\
\hline $\begin{array}{l}\text { 11. ZAP-70 } \\
\text { deficiency }\end{array}$ & $\begin{array}{l}\text { Decreased } \\
\text { CD8, normal } \\
\text { CD4 cells }\end{array}$ & Normal & Normal & & $A R$ & $\begin{array}{l}\text { Defects in ZAP-70 signaling } \\
\text { kinase }\end{array}$ & 176947 \\
\hline 12. $\mathrm{Ca}^{++}$chan & deficiency & & & & & & \\
\hline $\begin{array}{l}\text { (a) ORAI-I } \\
\text { deficiency* }\end{array}$ & $\begin{array}{l}\text { Normal } \\
\text { number, but } \\
\text { defective } \\
\text { TCR- } \\
\text { mediated } \\
\text { activation }\end{array}$ & Normal & Normal & $\begin{array}{l}\text { Autoimmunity, anhydrotic } \\
\text { ectodermic dysplasia, } \\
\text { non-progressive myopathy }\end{array}$ & AR & $\begin{array}{l}\text { Defect in ORAl-1, a } \mathrm{Ca}^{++} \\
\text {release-activated channel } \\
\text { (CRAC) modulatory } \\
\text { component }\end{array}$ & 610277 \\
\hline
\end{tabular}


Table 1 | Continued

\begin{tabular}{|c|c|c|c|c|c|c|c|}
\hline Disease & $\begin{array}{l}\text { Circulating } \\
\text { T cells }\end{array}$ & $\begin{array}{l}\text { Circulating } \\
\text { B cells }\end{array}$ & Serum Ig & $\begin{array}{l}\text { Associated } \\
\text { features }\end{array}$ & $\begin{array}{l}\text { Inheri- } \\
\text { tance }\end{array}$ & $\begin{array}{l}\text { Genetic defect/ } \\
\text { presumed } \\
\text { pathogenesis }\end{array}$ & $\begin{array}{l}\text { OMIM } \\
\text { number }\end{array}$ \\
\hline $\begin{array}{l}\text { (b) STIM-1 } \\
\text { deficiency* }\end{array}$ & $\begin{array}{l}\text { Normal } \\
\text { number, but } \\
\text { defective } \\
\text { TCR- } \\
\text { mediated } \\
\text { activation }\end{array}$ & Normal & Normal & $\begin{array}{l}\text { Autoimmunity, anhydrotic } \\
\text { ectodermic dysplasia, } \\
\text { non-progressive myopathy }\end{array}$ & $A R$ & $\begin{array}{l}\text { Defect in STIM-1, a stromal } \\
\text { interaction molecule } \\
\mathrm{Ca}^{++} \text {sensor }\end{array}$ & 605921 \\
\hline $\begin{array}{l}\text { 13. MHC } \\
\text { class I } \\
\text { deficiency }\end{array}$ & $\begin{array}{l}\text { Decreased } \\
\text { CD8, normal } \\
\text { CD4 }\end{array}$ & Normal & Normal & Vasculitis & $A R$ & $\begin{array}{l}\text { Mutations in TAP1, TAP2 or } \\
\text { TAPBP (tapasin) genes giving } \\
\text { MHC class I deficiency }\end{array}$ & 604571 \\
\hline $\begin{array}{l}\text { 14. MHC } \\
\text { class II } \\
\text { deficiency }\end{array}$ & $\begin{array}{l}\text { Normal } \\
\text { number, } \\
\text { decreased } \\
\text { CD4 cells }\end{array}$ & Normal & $\begin{array}{l}\text { Normal or } \\
\text { decreased }\end{array}$ & $\begin{array}{l}\text { Failure to thrive, diarrhea, } \\
\text { respiratory tract infections }\end{array}$ & $A R$ & $\begin{array}{l}\text { Mutation in transcription } \\
\text { factors for MHC class II } \\
\text { proteins (CIITA, RFX5, } \\
\text { RFXAP, RFXANK genes) }\end{array}$ & 209920 \\
\hline $\begin{array}{l}\text { 15. Winged } \\
\text { helix } \\
\text { deficiency } \\
\text { (nude)* }\end{array}$ & $\begin{array}{l}\text { Markedly } \\
\text { decreased }\end{array}$ & Normal & Decreased & $\begin{array}{l}\text { Alopecia, abnormal thymic } \\
\text { epithelium, impaired T cell } \\
\text { maturation (widely studied } \\
\text { nude mouse defect) }\end{array}$ & $A R$ & $\begin{array}{l}\text { Defects in forkhead box } \mathrm{N} 1 \\
\text { transcription factor encoded } \\
\text { by FOXN1, the gene mutated } \\
\text { in nude mice }\end{array}$ & 600838 \\
\hline $\begin{array}{l}\text { 16. Complete } \\
\text { DiGeorge } \\
\text { syndrome }\end{array}$ & $\begin{array}{l}\text { Profoundly } \\
\text { decreased }\end{array}$ & $\begin{array}{l}\text { Low to } \\
\text { normal }\end{array}$ & Decreased & $\begin{array}{l}\text { Lymphoproliferation } \\
\text { (lymphadenopathy, } \\
\text { hepatosplenomegaly), } \\
\text { autoimmunity (may resemble } \\
\text { IPEX syndrome), impaired T } \\
\text { cell proliferation }\end{array}$ & $A D$ & $\begin{array}{l}\text { Deletion of chromosome } \\
22 q 11.2 \text { or in a minority of } \\
\text { cases other chromosomal } \\
\text { regions, including } 10 \mathrm{p} ; \\
\text { heterozygous defects in } \\
\text { transcription factor TBX1 }\end{array}$ & 188400 \\
\hline $\begin{array}{l}\text { 17. Cartilage } \\
\text { hair } \\
\text { hypoplasia }\end{array}$ & $\begin{array}{l}\text { Decreased or } \\
\text { normal; } \\
\text { impaired } \\
\text { lymphocyte } \\
\text { proliferation }\end{array}$ & Normal & $\begin{array}{l}\text { Normal or } \\
\text { reduced. } \\
\text { Antibodies } \\
\text { variably } \\
\text { decreased }\end{array}$ & $\begin{array}{l}\text { Short-limbed dwarfism with } \\
\text { metaphyseal dysostosis, } \\
\text { sparse hair, bone marrow } \\
\text { failure, autoimmunity, } \\
\text { susceptibility to lymphoma } \\
\text { and other cancers, impaired } \\
\text { spermatogenesis, neuronal } \\
\text { dysplasia of the intestine }\end{array}$ & $A R$ & $\begin{array}{l}\text { Mutations in RMRP (RNase } \\
\text { MRP RNA) Involved in } \\
\text { processing of ribosomal RNA, } \\
\text { mitochondrial DNA replication } \\
\text { and cell cycle control }\end{array}$ & 250250 \\
\hline $\begin{array}{l}\text { 18. IKAROS } \\
\text { deficiency* }\end{array}$ & $\begin{array}{l}\text { Normal, but } \\
\text { impaired } \\
\text { lymphocyte } \\
\text { proliferation }\end{array}$ & Absent & $\begin{array}{l}\text { Presumably } \\
\text { decreased }\end{array}$ & $\begin{array}{l}\text { Anemia, neutropenia, } \\
\text { thrombocytopenia }\end{array}$ & $\begin{array}{l}\text { AD de } \\
\text { novo }\end{array}$ & $\begin{array}{l}\text { Mutation in IKAROS, a } \\
\text { hematopoietic specific } \\
\text { zinc-finger protein and a } \\
\text { central regulator of lymphoid } \\
\text { differentiation }\end{array}$ & \\
\hline $\begin{array}{l}\text { 19. STAT5b } \\
\text { deficiency* }\end{array}$ & $\begin{array}{l}\text { Modestly } \\
\text { decreased }\end{array}$ & Normal & Normal & $\begin{array}{l}\text { Growth-hormone insensitive } \\
\text { dwarfism, dysmorphic } \\
\text { features, eczema, } \\
\text { lymphocytic interstitial } \\
\text { pneumonitis, autoimmunity }\end{array}$ & $A R$ & $\begin{array}{l}\text { Defects of STAT5b, impaired } \\
\text { development and function of } \\
\gamma \delta T \text { cells, Treg, and NK cells, } \\
\text { impaired T cell proliferation }\end{array}$ & 604260 \\
\hline $\begin{array}{l}\text { 20. ITK } \\
\text { deficiency* }\end{array}$ & $\begin{array}{l}\text { Modestly } \\
\text { decreased }\end{array}$ & Normal & $\begin{array}{l}\text { Normal or } \\
\text { decreased }\end{array}$ & & $A R$ & $\begin{array}{l}\text { Defects in ITK, EBV } \\
\text { associated } \\
\text { lymphoproliferation }\end{array}$ & 613011 \\
\hline $\begin{array}{l}\text { 21. MAGT1 } \\
\text { deficiency* }\end{array}$ & $\begin{array}{l}\text { Decreased } \\
\text { CD4 cells }\end{array}$ & Normal & Normal & $\begin{array}{l}\text { EBV infection, lymphoma; } \\
\text { viral infections, respiratory } \\
\text { and GI infections }\end{array}$ & $X L$ & $\begin{array}{l}\text { Mutations in MAGT1, } \\
\text { impaired } \mathrm{Mg}^{++} \text {flux leading to } \\
\text { impaired TCR signaling }\end{array}$ & 300715 \\
\hline
\end{tabular}


Table 1 | Continued

\begin{tabular}{lllllll}
\hline Disease & $\begin{array}{l}\text { Circulating } \\
\text { T cells }\end{array}$ & $\begin{array}{l}\text { Circulating } \\
\text { B cells }\end{array}$ & Serum Ig & $\begin{array}{l}\text { Associated } \\
\text { features }\end{array}$ & $\begin{array}{l}\text { Inheri- } \\
\text { tance }\end{array}$ & $\begin{array}{l}\text { Genetic defect/ } \\
\text { presumed } \\
\text { pathogenesis }\end{array}$ \\
\hline $\begin{array}{l}\text { 22. DocK8 } \\
\text { deficiency }\end{array}$ & Decreased & Decreased & $\begin{array}{l}\text { Low lgM, } \\
\text { increased } \\
\text { IgE }\end{array}$ & $\begin{array}{l}\text { Low NK cells, } \\
\text { hypereosinophilia, recurrent } \\
\text { infections; severe atopy, } \\
\text { extensive cutaneous viral, and } \\
\text { bacterial (staph.) infections, } \\
\text { susceptibility to cancer }\end{array}$ & AR & Defect in DOCK8 \\
& & & &
\end{tabular}

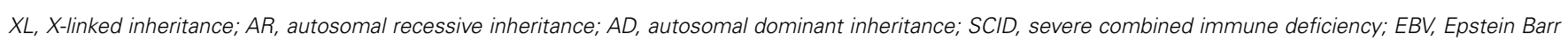
virus; $\mathrm{Ca}^{++}$, calcium; $\mathrm{MHC}$, major histocompatibility complex.

*Ten or fewer unrelated cases reported in the literature.

Three disorders have been added to Table 1: DOCK8 deficiency, IKAROS deficiency, and MAGT1 deficiency.

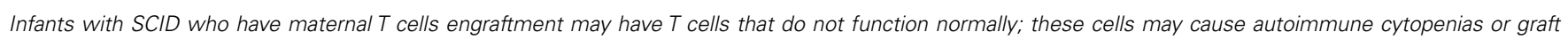

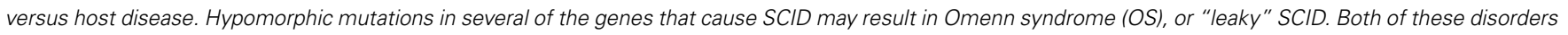

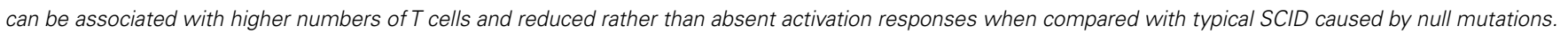

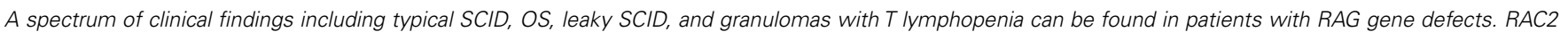

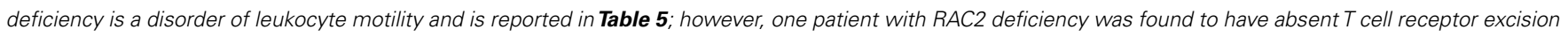

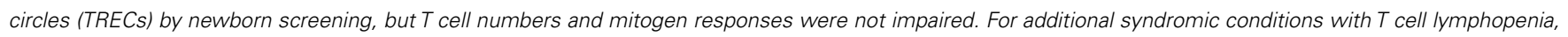

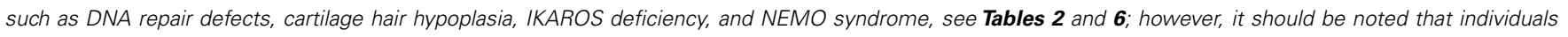

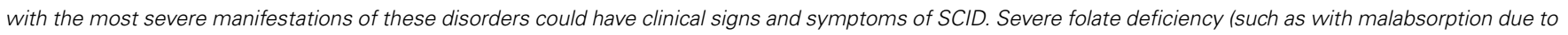

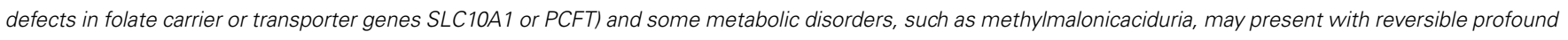
lymphopenia in addition to their characteristic presenting features. 
Table 2 | Well-defined syndromes with immunodeficiency.

\begin{tabular}{|c|c|c|c|c|c|c|c|}
\hline Disease & $\begin{array}{l}\text { Circulating } \\
\text { T cells }\end{array}$ & $\begin{array}{l}\text { Circulating } \\
\text { B cells }\end{array}$ & Serum Ig & $\begin{array}{l}\text { Associated } \\
\text { features }\end{array}$ & $\begin{array}{l}\text { Inheri- } \\
\text { tance }\end{array}$ & $\begin{array}{l}\text { Genetic defect/ } \\
\text { presumed } \\
\text { pathogenesis }\end{array}$ & $\begin{array}{l}\text { OMIM } \\
\text { number }\end{array}$ \\
\hline \multicolumn{8}{|c|}{ 2. DNA repair defects (other than those in Table 1) } \\
\hline $\begin{array}{l}\text { (b) Ataxia- } \\
\text { telangiectasia-like } \\
\text { disease (ATLD)* }\end{array}$ & $\begin{array}{l}\text { Progressive } \\
\text { decrease }\end{array}$ & Normal & $\begin{array}{l}\text { Antibodies } \\
\text { variably } \\
\text { decreased }\end{array}$ & $\begin{array}{l}\text { Moderate ataxia; pulmonary } \\
\text { infections; severely increased } \\
\text { radiosensitivity }\end{array}$ & $A R$ & $\begin{array}{l}\text { Hypomorphic } \\
\text { mutations in } \\
\text { MRE11; disorder of } \\
\text { cell cycle } \\
\text { checkpoint and } \\
\text { DNA double- } \\
\text { strand break repair }\end{array}$ & 604391 \\
\hline $\begin{array}{l}\text { (d) Bloom } \\
\text { syndrome }\end{array}$ & Normal & Normal & Reduced & $\begin{array}{l}\text { Short stature; bird like face; } \\
\text { sun-sensitive erythema; marrow } \\
\text { failure; leukemia; lymphoma; } \\
\text { chromosomal instability }\end{array}$ & $A R$ & $\begin{array}{l}\text { Mutations in } B L M \text {; } \\
\text { RecQ like helicase }\end{array}$ & 210900 \\
\hline $\begin{array}{l}\text { (e) Immunodefi- } \\
\text { ciency with } \\
\text { centromeric } \\
\text { instability and } \\
\text { facial anomalies } \\
\text { (ICF) }\end{array}$ & $\begin{array}{l}\text { Decreased or } \\
\text { normal; } \\
\text { Responses } \\
\text { to PHA may } \\
\text { be decreased }\end{array}$ & $\begin{array}{l}\text { Decreased or } \\
\text { normal }\end{array}$ & $\begin{array}{l}\text { Hypogamma- } \\
\text { globulinemia; } \\
\text { variable antibody } \\
\text { deficiency }\end{array}$ & $\begin{array}{l}\text { Facial dysmorphic features; } \\
\text { macroglossia; } \\
\text { bacterial/opportunistic infections; } \\
\text { malabsorption; cytopenias; } \\
\text { malignancies; multiradial } \\
\text { configurations of chromosomes } \\
\text { 1,9,16; no DNA breaks }\end{array}$ & AR & $\begin{array}{l}\text { Mutations in DNA } \\
\text { methyltransferase } \\
\text { DNMT3B (ICF1) } \\
\text { resulting in } \\
\text { defective DNA } \\
\text { methylation; or in } \\
\text { ZBTB24 (ICF2) }\end{array}$ & 242860 \\
\hline
\end{tabular}


Table 2 | Continued

\begin{tabular}{|c|c|c|c|c|c|c|c|}
\hline Disease & $\begin{array}{l}\text { Circulating } \\
\text { T cells }\end{array}$ & $\begin{array}{l}\text { Circulating } \\
\text { B cells }\end{array}$ & Serum Ig & $\begin{array}{l}\text { Associated } \\
\text { features }\end{array}$ & $\begin{array}{l}\text { Inheri- } \\
\text { tance }\end{array}$ & $\begin{array}{l}\text { Genetic defect/ } \\
\text { presumed } \\
\text { pathogenesis }\end{array}$ & $\begin{array}{l}\text { OMIM } \\
\text { number }\end{array}$ \\
\hline $\begin{array}{l}\text { (g) Riddle } \\
\text { syndrome* }\end{array}$ & Normal & Normal & Low IgG & $\begin{array}{l}\text { Mild motor control and learning } \\
\text { difficulties, mild facial } \\
\text { dysmorphism, and short stature }\end{array}$ & $A R$ & $\begin{array}{l}\text { Mutations in } \\
R N F 168 \text {, resulting } \\
\text { in defective DNA } \\
\text { double-strand } \\
\text { break repair }\end{array}$ & 611943 \\
\hline $\begin{array}{l}\text { DiGeorge } \\
\text { anomaly } \\
\text { (chromosome } \\
22 q 11.2 \text { deletion } \\
\text { syndrome) }\end{array}$ & $\begin{array}{l}\text { Decreased or } \\
\text { normal }\end{array}$ & Normal & $\begin{array}{l}\text { Normal or } \\
\text { decreased }\end{array}$ & $\begin{array}{l}\text { Hypoparathyroidism, conotruncal } \\
\text { malformation; abnormal facies; } \\
\text { large deletion ( } 3 \mathrm{Mb} \text { ) in } 22 \mathrm{q} 11.2 \\
\text { (or rarely a deletion in } 10 \mathrm{p} \text { ) }\end{array}$ & $\begin{array}{l}\text { De } \\
\text { novo } \\
\text { defect } \\
\text { or AD }\end{array}$ & $\begin{array}{l}\text { Contiguous gene } \\
\text { defect in } 90 \% \\
\text { affecting thymic } \\
\text { development; } \\
\text { mutation in } T B X 1\end{array}$ & 188400 \\
\hline \multicolumn{8}{|c|}{ 4. Immune-osseous dysplasias } \\
\hline $\begin{array}{l}\text { (a) Cartilage hair } \\
\text { hypoplasia }\end{array}$ & $\begin{array}{l}\text { Decreased or } \\
\text { normal; } \\
\text { impaired } \\
\text { lymphocyte } \\
\text { proliferation }\end{array}$ & Normal & $\begin{array}{l}\text { Normal or } \\
\text { reduced. } \\
\text { Antibodies } \\
\text { variably } \\
\text { decreased }\end{array}$ & $\begin{array}{l}\text { Short-limbed dwarfism with } \\
\text { metaphyseal dysostosis, sparse } \\
\text { hair, bone marrow failure, } \\
\text { autoimmunity, susceptibility to } \\
\text { lymphoma and other cancers, } \\
\text { impaired spermatogenesis, } \\
\text { neuronal dysplasia of the } \\
\text { intestine }\end{array}$ & $A R$ & $\begin{array}{l}\text { Mutations in RMRP } \\
\text { (RNase MRP RNA) } \\
\text { Involved in } \\
\text { processing of } \\
\text { ribosomal RNA, } \\
\text { mitochondrial DNA } \\
\text { replication and cell } \\
\text { cycle control }\end{array}$ & 250250 \\
\hline $\begin{array}{l}\text { 5. Comel- } \\
\text { Netherton } \\
\text { syndrome }\end{array}$ & Normal & $\begin{array}{l}\text { Switched and } \\
\text { non-switched } \\
\text { B cells are } \\
\text { reduced }\end{array}$ & $\begin{array}{l}\text { Elevated IgE and } \\
\text { IgA antibody } \\
\text { variably } \\
\text { decreased }\end{array}$ & $\begin{array}{l}\text { Congenital ichthyosis, bamboo } \\
\text { hair, atopic diathesis, increased } \\
\text { bacterial infections, failure to } \\
\text { thrive }\end{array}$ & $A R$ & $\begin{array}{l}\text { Mutations in } \\
\text { SPINK } 5 \text { resulting } \\
\text { in lack of the serine } \\
\text { protease inhibitor } \\
\text { LEKTI, expressed } \\
\text { in epithelial cells }\end{array}$ & 256500 \\
\hline \multicolumn{8}{|c|}{ 6. Hyper-IgE syndromes (HIES) } \\
\hline $\begin{array}{l}\text { (a) AD-HIES (Job } \\
\text { syndrome) }\end{array}$ & $\begin{array}{l}\text { Normal Th-17 } \\
\text { cells } \\
\text { decreased }\end{array}$ & $\begin{array}{l}\text { Normal } \\
\text { (switched } \\
\text { and } \\
\text { non-switched } \\
\text { memory B } \\
\text { cells are } \\
\text { reduced; } \\
\text { BAFF level } \\
\text { increased) }\end{array}$ & $\begin{array}{l}\text { Elevated IgE; } \\
\text { specific antibody } \\
\text { production } \\
\text { decreased }\end{array}$ & $\begin{array}{l}\text { Distinctive facial features (broad } \\
\text { nasal bridge), eczema, } \\
\text { osteoporosis, and fractures, } \\
\text { scoliosis, failure/delay of } \\
\text { shedding primary teeth, } \\
\text { hyperextensible joints, bacterial } \\
\text { infections (skin and pulmonary } \\
\text { abscesses, pneumatoceles) due } \\
\text { to Staphylococcus aureus, } \\
\text { candidiasis }\end{array}$ & $\begin{array}{l}\text { AD, } \\
\text { often } \\
\text { de } \\
\text { novo } \\
\text { defect }\end{array}$ & $\begin{array}{l}\text { Dominant-negative } \\
\text { heterozygous } \\
\text { mutations in STAT3 }\end{array}$ & \\
\hline
\end{tabular}


Table 2 | Continued

\begin{tabular}{|c|c|c|c|c|c|c|c|}
\hline Disease & $\begin{array}{l}\text { Circulating } \\
T \text { cells }\end{array}$ & $\begin{array}{l}\text { Circulating } \\
\text { B cells }\end{array}$ & Serum Ig & $\begin{array}{l}\text { Associated } \\
\text { features }\end{array}$ & $\begin{array}{l}\text { Inheri- } \\
\text { tance }\end{array}$ & $\begin{array}{l}\text { Genetic defect/ } \\
\text { presumed } \\
\text { pathogenesis }\end{array}$ & $\begin{array}{l}\text { OMIM } \\
\text { number }\end{array}$ \\
\hline $\begin{array}{l}\text { (ii) DOCK8 } \\
\text { deficiency }\end{array}$ & Reduced & Reduced & $\begin{array}{l}( \pm) \text { Elevated lgE, } \\
\text { low IgM }\end{array}$ & $\begin{array}{l}\text { Recurrent respiratory infections; } \\
\text { extensive cutaneous viral and } \\
\text { staphylococcal infections, } \\
\text { increased risk of cancer, severe } \\
\text { atopy with anaphylaxis }\end{array}$ & & $\begin{array}{l}\text { Mutation in } \\
\text { DOCK } 8\end{array}$ & 611432 \\
\hline $\begin{array}{l}\text { (iii) Unknown } \\
\text { origin }\end{array}$ & Normal & Normal & Elevated IgE & $\begin{array}{l}\text { CNS hemorrhage, fungal, and } \\
\text { viral infections }\end{array}$ & & Unknown & \\
\hline $\begin{array}{l}\text { 7. Hepatic } \\
\text { veno-occlusive } \\
\text { disease with } \\
\text { immunodefi- } \\
\text { ciency } \\
\text { (VODI) }\end{array}$ & $\begin{array}{l}\text { Normal } \\
\text { (decreased } \\
\text { memory } T \\
\text { cells) }\end{array}$ & $\begin{array}{l}\text { Normal } \\
\text { (decreased } \\
\text { memory B } \\
\text { cells) }\end{array}$ & $\begin{array}{l}\text { Decreased lgG, } \\
\text { IgA, IgM absent } \\
\text { germinal centers } \\
\text { absent tissue } \\
\text { plasma cells }\end{array}$ & $\begin{array}{l}\text { Hepatic veno-occlusive disease; } \\
\text { Pneumocystis jiroveci } \\
\text { pneumonia; susceptibility to } \\
\text { CMV, candida; } \\
\text { thrombocytopenia; } \\
\text { hepatosplenomegaly }\end{array}$ & $A R$ & Mutations in SP110 & 235550 \\
\hline \multicolumn{8}{|c|}{ 8. Dyskeratosis congenita (DKC) } \\
\hline $\begin{array}{l}\text { (a) XL-DKC } \\
\text { (Hoyeraal- } \\
\text { Hreidarsson } \\
\text { syndrome) }\end{array}$ & $\begin{array}{l}\text { Progressive } \\
\text { decrease }\end{array}$ & $\begin{array}{l}\text { Progressive } \\
\text { decrease }\end{array}$ & Variable & $\begin{array}{l}\text { Intrauterine growth retardation, } \\
\text { microcephaly, nail dystrophy, } \\
\text { recurrent infections, digestive } \\
\text { tract involvement, pancytopenia, } \\
\text { reduced number and function of } \\
\text { NK cells }\end{array}$ & $X \mathrm{~L}$ & $\begin{array}{l}\text { Mutations in } \\
\text { dyskerin }(D K C 1)\end{array}$ & 305000 \\
\hline (c) AD-DKC & Variable & Variable & Variable & $\begin{array}{l}\text { Reticular hyperpigmentation of } \\
\text { the skin, dystrophic nails, } \\
\text { osteoporosis, premalignant } \\
\text { leukokeratosis of the mouth } \\
\text { mucosa, palmar hyperkeratosis, } \\
\text { anemia, pancytopenia }\end{array}$ & $A D$ & $\begin{array}{l}\text { Mutation in TERT } \\
\text { Mutation in TINF2 }\end{array}$ & 127550 \\
\hline
\end{tabular}


Table 2 | Continued

\begin{tabular}{|c|c|c|c|c|c|c|c|}
\hline Disease & $\begin{array}{l}\text { Circulating } \\
\text { T cells }\end{array}$ & $\begin{array}{l}\text { Circulating } \\
\text { B cells }\end{array}$ & Serum Ig & $\begin{array}{l}\text { Associated } \\
\text { features }\end{array}$ & $\begin{array}{l}\text { Inheri- } \\
\text { tance }\end{array}$ & $\begin{array}{l}\text { Genetic defect/ } \\
\text { presumed } \\
\text { pathogenesis }\end{array}$ & $\begin{array}{l}\text { OMIM } \\
\text { number }\end{array}$ \\
\hline
\end{tabular}

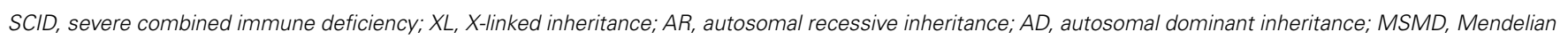
susceptibility of mycobacterial disease.

*Ten or fewer unrelated cases reported in the literature.

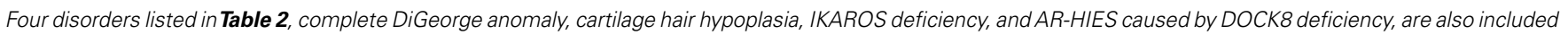

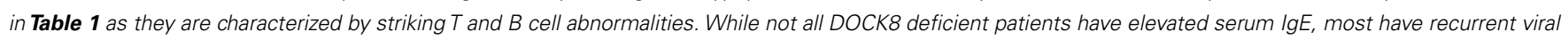

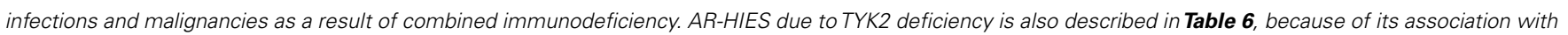

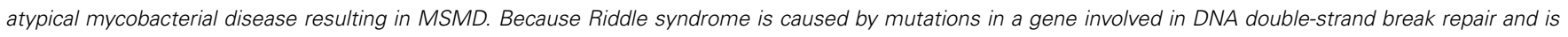
associated with hypogammaglobulinemia, we have added this rare syndrome to Table 2. Chronic mucocutaneous candidiasis (CMC) has been moved to Table 6 . Autosomal dominant and autosomal recessive forms of Dyskeratosis congenita, caused by mutations of recently identified genes, have been included in this table.

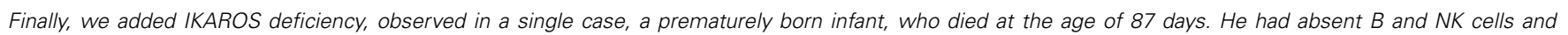
non-functional T cells, suggesting combined immunodeficiency. 
Table 3 | Predominantly antibody deficiencies.

\begin{tabular}{|c|c|c|c|c|c|}
\hline Disease & Serum Ig & Associated features & Inheritance & $\begin{array}{l}\text { Genetic defect/ } \\
\text { presumed } \\
\text { pathogenesis }\end{array}$ & $\begin{array}{l}\text { OMIM } \\
\text { number }\end{array}$ \\
\hline (a) BTK deficiency & $\begin{array}{l}\text { All isotypes decreased in } \\
\text { majority of patients; some } \\
\text { patients have detectable } \\
\text { immunoglobulins }\end{array}$ & $\begin{array}{l}\text { Severe bacterial infections; } \\
\text { normal numbers of pro-B cells }\end{array}$ & $X \mathrm{~L}$ & $\begin{array}{l}\text { Mutations in BTK, a } \\
\text { cytoplasmic tyrosine } \\
\text { kinase activated by } \\
\text { crosslinking of the BCR }\end{array}$ & 300300 \\
\hline $\begin{array}{l}\text { (b) } \mu \text { Heavy chain } \\
\text { deficiency }\end{array}$ & All isotypes decreased & $\begin{array}{l}\text { Severe bacterial infections; } \\
\text { normal numbers of pro-B cells }\end{array}$ & $A R$ & $\begin{array}{l}\text { Mutations in } \mu \text { heavy } \\
\text { chain }\end{array}$ & 147020 \\
\hline (c) $\lambda 5$ deficiency* & All isotypes decreased & $\begin{array}{l}\text { Severe bacterial infections; } \\
\text { normal numbers of pro-B cells }\end{array}$ & $A R$ & $\begin{array}{l}\text { Mutations in } \lambda 5 \text {; part of } \\
\text { the surrogate light chain } \\
\text { in the pre-BCR }\end{array}$ & 146770 \\
\hline (e) $\lg \beta$ deficiency* & All isotypes decreased & $\begin{array}{l}\text { Severe bacterial infections; } \\
\text { normal numbers of pro-B cells }\end{array}$ & $A R$ & $\begin{array}{l}\text { Mutations in } \lg \beta \\
(C D 79 b) ; \text { part of the } \\
\text { pre-BCR and } B C R\end{array}$ & 147245 \\
\hline (f) BLNK deficiency* & All isotypes decreased & $\begin{array}{l}\text { Severe bacterial infections; } \\
\text { normal numbers of pro-B cells }\end{array}$ & $A R$ & $\begin{array}{l}\text { Mutations in BLNK; a } \\
\text { scaffold protein that } \\
\text { binds to BTK }\end{array}$ & 604615 \\
\hline $\begin{array}{l}\text { (g) Thymoma with } \\
\text { immunodeficiency }\end{array}$ & $\begin{array}{l}\text { One or more isotypes may } \\
\text { be decreased }\end{array}$ & $\begin{array}{l}\text { Bacterial and opportunistic } \\
\text { infections; autoimmunity; } \\
\text { decreased number of pro-B cells }\end{array}$ & None & Unknown & \\
\hline (b) ICOS deficiency* & $\begin{array}{l}\text { Low } \lg G \text { and } \lg A \text { and/or } \\
\lg M\end{array}$ & & $A R$ & Mutations in ICOS & 604558 \\
\hline (c) CD19 deficiency* & $\begin{array}{l}\text { Low } \lg G \text { and } \lg A \text { and/or } \\
\lg M\end{array}$ & May have glomerulonephritis & $A R$ & $\begin{array}{l}\text { Mutations in CD19; } \\
\text { transmembrane protein } \\
\text { that amplifies signal } \\
\text { through BCR }\end{array}$ & 107265 \\
\hline (d) CD81 deficiency* & $\begin{array}{l}\text { Low lgG, low or normal } \\
\lg A \text {, and IgM }\end{array}$ & May have glomerulonephritis & $A R$ & $\begin{array}{l}\text { Mutations in } C D 81 \text {; } \\
\text { transmembrane protein } \\
\text { that amplifies signal } \\
\text { through BCR }\end{array}$ & 186845 \\
\hline (e) CD20 deficiency* & $\begin{array}{l}\text { Low IgG, normal or } \\
\text { elevated IgM, and } \lg A\end{array}$ & & $A R$ & Mutations in $C D 20$ & 112210 \\
\hline
\end{tabular}


Table 3 | Continued

\begin{tabular}{|c|c|c|c|c|c|}
\hline Disease & Serum Ig & Associated features & Inheritance & $\begin{array}{l}\text { Genetic defect/ } \\
\text { presumed } \\
\text { pathogenesis }\end{array}$ & $\begin{array}{l}\text { OMIM } \\
\text { number }\end{array}$ \\
\hline $\begin{array}{l}\text { (g) BAFF receptor } \\
\text { deficiency* }\end{array}$ & Low $\lg G$ and $\lg M$ & Variable clinical expression & $A R$ & $\begin{array}{l}\text { Mutations in } \\
\text { TNFRSF13C (BAFF-R) }\end{array}$ & 606269 \\
\hline (a) CD40L deficiency & $\begin{array}{l}\text { IgG and IgA decreased; } \\
\text { IgM may be normal or } \\
\text { increased; B cell numbers } \\
\text { may be normal or } \\
\text { increased }\end{array}$ & $\begin{array}{l}\text { Opportunistic infections, } \\
\text { neutropenia, autoimmune } \\
\text { disease }\end{array}$ & $X L$ & $\begin{array}{l}\text { Mutations in CD40LG } \\
\text { (also called TNFSF5 or } \\
\text { CD154) }\end{array}$ & 300386 \\
\hline (c) AID deficiency & $\begin{array}{l}\lg G \text { and } \lg A \text { decreased; } \\
\operatorname{lgM} \text { increased }\end{array}$ & $\begin{array}{l}\text { Enlarged lymph nodes and } \\
\text { germinal centers }\end{array}$ & $A R$ & $\begin{array}{l}\text { Mutations in AICDA } \\
\text { gene }\end{array}$ & 605257 \\
\hline (d) UNG deficiency & $\begin{array}{l}\lg G \text { and } \lg A \text { decreased; } \\
\operatorname{lgM} \text { increased }\end{array}$ & $\begin{array}{l}\text { Enlarged lymph nodes and } \\
\text { germinal centers }\end{array}$ & $A R$ & Mutations in UNG & 191525 \\
\hline \multicolumn{6}{|c|}{ 4. Isotype or light chain deficiencies with normal numbers of B cells } \\
\hline $\begin{array}{l}\text { (a) Ig heavy chain } \\
\text { mutations and deletions }\end{array}$ & $\begin{array}{l}\text { One or more lgG and/or } \\
\text { IgA subclasses as well as } \\
\text { lgE may be absent }\end{array}$ & May be asymptomatic & $A R$ & $\begin{array}{l}\text { Mutation or } \\
\text { chromosomal deletion } \\
\text { at } 14 q 32\end{array}$ & \\
\hline (b) $\kappa$ chain deficiency* & $\begin{array}{l}\text { All immunoglobulins have } \\
\text { lambda light chain }\end{array}$ & Asymptomatic & $A R$ & $\begin{array}{l}\text { Mutations in } \kappa \text { constant } \\
\text { gene }\end{array}$ & 147200 \\
\hline $\begin{array}{l}\text { (d) IgA with IgG } \\
\text { subclass deficiency }\end{array}$ & $\begin{array}{l}\text { Reduced IgA with } \\
\text { decrease in one or more } \\
\text { IgG subclass }\end{array}$ & $\begin{array}{l}\text { Recurrent bacterial infections in } \\
\text { majority }\end{array}$ & Variable & Unknown & \\
\hline $\begin{array}{l}\text { (e) Selective IgA } \\
\text { deficiency }\end{array}$ & $\lg A$ decreased/absent & $\begin{array}{l}\text { Usually asymptomatic; may have } \\
\text { recurrent infections with poor } \\
\text { antibody responses to } \\
\text { carbohydrate antigens; may have } \\
\text { allergies or autoimmune disease. } \\
\text { A very few cases progress to } \\
\text { CVID, others coexist with CVID } \\
\text { in the family }\end{array}$ & Variable & Unknown & \\
\hline $\begin{array}{l}\text { 5. Specific antibody } \\
\text { deficiency with } \\
\text { normal lg } \\
\text { concentrations and } \\
\text { normal numbers of } \\
\text { B cells }\end{array}$ & Normal & $\begin{array}{l}\text { Reduced ability to make } \\
\text { antibodies to specific antigens }\end{array}$ & Variable & Unknown & \\
\hline
\end{tabular}


Table 3 | Continued

\begin{tabular}{|c|c|c|c|c|c|}
\hline Disease & Serum Ig & Associated features & Inheritance & $\begin{array}{l}\text { Genetic defect/ } \\
\text { presumed } \\
\text { pathogenesis }\end{array}$ & $\begin{array}{l}\text { OMIM } \\
\text { number }\end{array}$ \\
\hline
\end{tabular}

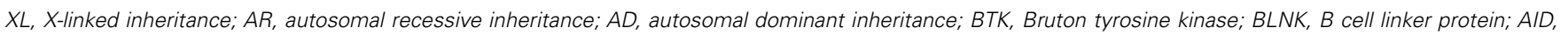
activation-induced cytidine deaminase; UNG, uracil-DNA glycosylase; ICOS, inducible costimulator; lg( $\mathrm{k}$ ), immunoglobulin, or $\kappa$ light chain type.

*Ten or fewer unrelated cases reported in the literature.

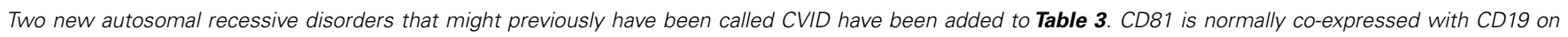

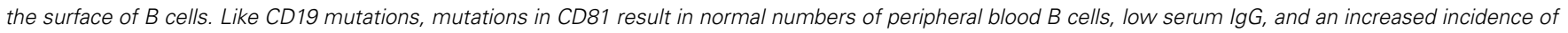
glomerulonephritis. A single patient with a homozygous mutation in CD20 has been reported.

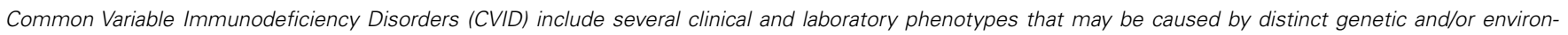

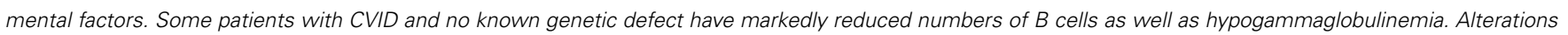

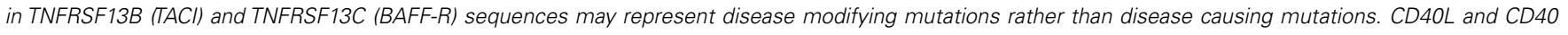

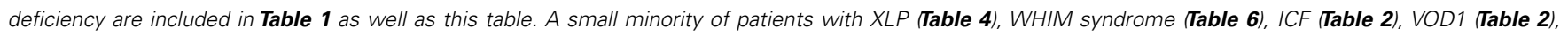

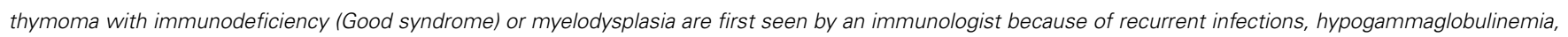

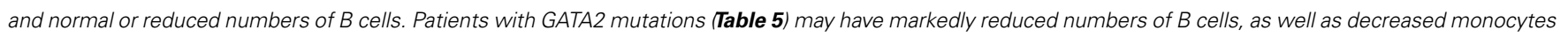
and NK cells and a predisposition to myelodysplasia but they do not have an antibody deficiency. 
Table 4 | Diseases of immune dysregulation.

\begin{tabular}{|c|c|c|c|c|c|c|c|}
\hline Disease & $\begin{array}{l}\text { Circulating } \\
\text { T cells }\end{array}$ & $\begin{array}{l}\text { Circulating } \\
\text { B cells }\end{array}$ & Serum Ig & $\begin{array}{l}\text { Associated } \\
\text { features }\end{array}$ & $\begin{array}{l}\text { Inheri- } \\
\text { tance }\end{array}$ & $\begin{array}{l}\text { Genetic defect/ } \\
\text { presumed } \\
\text { pathogenesis }\end{array}$ & $\begin{array}{l}\text { OMIM } \\
\text { number }\end{array}$ \\
\hline
\end{tabular}

\section{Immunodeficiency with hypopigmentation}

\begin{tabular}{|c|c|c|c|c|}
\hline $\begin{array}{l}\text { (a) Chediak- } \\
\text { Higashi } \\
\text { syndrome }\end{array}$ & Normal & Normal & Normal & $\begin{array}{l}\text { Partial albinism, recurrent } \\
\text { infections, late-onset primary } \\
\text { encephalopathy, increased } \\
\text { lymphoma risk. Neutropenia, } \\
\text { Giant lysosomes, low NK, and } \\
\text { CTL activities, elevation of acute } \\
\text { phase markers }\end{array}$ \\
\hline
\end{tabular}

\begin{tabular}{|c|c|c|c|c|}
\hline $\begin{array}{l}\text { (b) Griscelli } \\
\text { syndrome, } \\
\text { type2 }\end{array}$ & Normal & Normal & Normal & $\begin{array}{l}\text { Partial albinism, elevation of } \\
\text { acute phase markers, } \\
\text { encephalopathy in some } \\
\text { patients. Low NK and CTL } \\
\text { activities }\end{array}$ \\
\hline $\begin{array}{l}\text { (c) Hermansky- } \\
\text { Pudlak } \\
\text { syndrome, }\end{array}$ & Normal & Normal & Normal & $\begin{array}{l}\text { Partial albinism, increased } \\
\text { bleeding. Neutropenia, low NK, } \\
\text { and CTL activity }\end{array}$ \\
\hline
\end{tabular}

type $2^{*}$

\section{Familial hemophagocytic lymphohistiocytosis (FHL) syndromes}

\begin{tabular}{|c|c|c|c|c|}
\hline $\begin{array}{l}\text { (a) Perforin } \\
\text { deficiency, } \\
\text { FHL2 }\end{array}$ & Normal & Normal & Normal & $\begin{array}{l}\text { Severe inflammation, persistent } \\
\text { fever, cytopenias, splenomegaly. } \\
\text { Hemophagocytosis, decreased } \\
\text { to absent NK and CTL activities }\end{array}$ \\
\hline $\begin{array}{l}\text { (b) UNC13D } \\
\text { (Munc13-4) } \\
\text { deficiency, } \\
\text { FHL3 }\end{array}$ & Normal & Normal & Normal & $\begin{array}{l}\text { Severe inflammation, persistent } \\
\text { fever, splenomegaly, } \\
\text { hemophagocytosis, decreased } \\
\text { NK and CTL activities }\end{array}$ \\
\hline
\end{tabular}

AR Mutations in PRF1; perforin, a major cytolytic protein
Mutations in RAB27A encoding a GTPase that promotes docking of secretory vesicles to the cell membrane

607624

AR Mutations in the $A P 3 B 1$ gene, encoding for the $\beta$ subunit of the AP-3 complex required to prime vesicles for fusion (*as named in OMIM). Note that also in OMIM the "official" name is UNC13D deficiency with the alternative title of MUNC13D deficiency

(c) Syntaxin 11 Normal Normal Normal deficiency,

FHL4

$\begin{array}{ll}\text { (d) STXBP2 Normal Normal } & \text { Normal or } \\ \text { (Munc 18-2) } & \\ \text { deficiency, } & \\ \text { FHL5 } & \end{array}$

\section{Severe inflammation, persistent fever, splenomegaly. Hemophagocytosis, decreased to absent NK activity}

Severe inflammation, fever, splenomegaly, hemophagocytosis possible bowel disease. Decreased NK and CTL activities with partial restoration after IL-2 stimulation
AR

Mutations in STX11, required

for fusion of secretory

vesicles with the cell

membrane and release of contents

Mutations in STXBP2, secretory vesicles with the cell membrane and release of contents 
Table 4 | Continued

Disease

\section{Circulating \\ T cells \\ Circulating $B$ cells \\ Serum Ig \\ Associated \\ features}

\section{Inheri- Genetic defect/ \\ tance presumed pathogenesis}

OMIM

number

\section{Lymphoproliferative syndromes}

\begin{tabular}{|c|c|c|c|}
\hline $\begin{array}{l}\text { (a) SH2D1A } \\
\text { deficiency, XLP1 }\end{array}$ & Normal & $\begin{array}{l}\text { Normal or } \\
\text { reduced }\end{array}$ & $\begin{array}{l}\text { Normal or } \\
\text { low }\end{array}$ \\
\hline
\end{tabular}
abnormalities triggered by EBV infection, including hepatitis, hemophagocytic syndrome, aplastic anemia, and lymphoma.

Dysgammaglobulinemia or hypogammaglobulinemia, low to absent NKT cells

\begin{tabular}{|c|c|c|c|}
\hline $\begin{array}{l}\text { (b) XIAP } \\
\text { deficiency, XLP2 }\end{array}$ & Normal & $\begin{array}{l}\text { Normal or } \\
\text { reduced }\end{array}$ & $\begin{array}{l}\text { Normal or } \\
\text { low }\end{array}$ \\
\hline
\end{tabular}

\section{Syndromes with autoimmunity}

(a) Autoimmune lymphoproliferative syndrome

(ALPS)

(v) Activating

(i) ALPS-FAS

Increased

$\mathrm{CD}^{-}{ }^{-} \mathrm{CD}^{-}$

double

negative

(DN) T cells

\begin{tabular}{|c|c|c|}
\hline (ii) ALPS- & Increased & Normal \\
\hline FASLG & DNT cells & \\
\hline
\end{tabular}

(iii) ALPS- Increased

CASP10* DNT cells

(iv) Caspase 8

defect*

N-RAS defect,

activating

Increased or

normal DNT

Elevation of

CD5 B cells

number of

$\mathrm{CD}^{+} \mathrm{B}$ cells

K-RAS defect* cells
Clinical and immunologic abnormalities triggered by EBV infection, including splenomegaly, hepatitis, hemophagocytic syndrome colitis
Normal or

increased

Splenomegaly, adenopathies autoimmune cytopenias, increased lymphoma risk. Defective lymphocyte apoptosis

Splenomegaly, adenopathies, autoimmune cytopenias, SLE defective lymphocyte apoptosis

Adenopathies, splenomegaly، autoimmunity. Defective lymphocyte apoptosis

Normal or decreased

Adenopathies, splenomegaly, recurrent bacterial, and viral infections. Defective lymphocyte apoptosis and activation,

hypogammaglobulinemia

Normal

Adenopathies, splenomegaly,

leukemia, Iymphoma.

Defective lymphocyte apoptosis following IL-2 withdrawal
$\mathrm{XL} \quad$ Mutations in XIAP encoding an inhibitor of apoptosis

\section{Mutations in SH2D1A encoding an adaptor protein regulating intracellular signals}

308240
AD (AR Mutations in TNFRSF6, cell
cases surface apoptosis receptor; in are addition to germline
rare mutations, somatic mutations and cause a similar phenotype severe) (ALPS-sFAS)

AD AR Mutations in TNFSF6, ligand for CD95 apoptosis receptor

134638

603909

utations in CASP10 intracellular apoptosis pathway

Mutations in CASP8, intracellular apoptosis and activation pathways
Sporadic Somatic mutations in NRAS encoding a GTP binding protein with diverse signaling functions; activating mutations impair mitochondrial apoptosis 
Table 4 | Continued

\begin{tabular}{|c|c|c|c|c|c|c|c|}
\hline Disease & $\begin{array}{l}\text { Circulating } \\
\text { T cells }\end{array}$ & $\begin{array}{l}\text { Circulating } \\
\text { B cells }\end{array}$ & Serum Ig & $\begin{array}{l}\text { Associated } \\
\text { features }\end{array}$ & $\begin{array}{l}\text { Inheri- } \\
\text { tance }\end{array}$ & $\begin{array}{l}\text { Genetic defect/ } \\
\text { presumed } \\
\text { pathogenesis }\end{array}$ & $\begin{array}{l}\text { OMIM } \\
\text { number }\end{array}$ \\
\hline $\begin{array}{l}\text { (vi) FADD } \\
\text { defi- } \\
\text { ciency* }^{*}\end{array}$ & $\begin{array}{l}\text { Increased DNT } \\
\text { cells }\end{array}$ & Normal & Normal & $\begin{array}{l}\text { Functional hyposplenism, } \\
\text { recurrent bacterial, and viral } \\
\text { infections, recurrent episodes } \\
\text { of encephalopathy and liver } \\
\text { dysfunction. Defective } \\
\text { lymphocyte apoptosis }\end{array}$ & AR & $\begin{array}{l}\text { Mutations in FADD encoding } \\
\text { an adaptor molecule } \\
\text { interacting with FAS, and } \\
\text { promoting apoptosis, } \\
\text { inflammation and innate } \\
\text { immunity }\end{array}$ & 613759 \\
\hline $\begin{array}{l}\text { (b) APECED } \\
\text { (APS-1), } \\
\text { autoimmune } \\
\text { polyendocrino- } \\
\text { pathy with } \\
\text { candidiasis } \\
\text { and } \\
\text { ectodermal } \\
\text { dystrophy }\end{array}$ & Normal & Normal & Normal & $\begin{array}{l}\text { Autoimmunity, particularly of } \\
\text { parathyroid, adrenal, and } \\
\text { other endocrine organs, } \\
\text { chronic candidiasis, dental } \\
\text { enamel hypoplasia, and other } \\
\text { abnormalities }\end{array}$ & $A R$ & $\begin{array}{l}\text { Mutations in } A I R E \text {, encoding } \\
\text { a transcription regulator } \\
\text { needed to establish thymic } \\
\text { self-tolerance }\end{array}$ & 240300 \\
\hline $\begin{array}{l}\text { (c) IPEX, } \\
\text { immune dys- } \\
\text { regulation, } \\
\text { polyendo- } \\
\text { crinopathy, } \\
\text { enteropathy } \\
\text { (X-linked) }\end{array}$ & $\begin{array}{l}\text { Lack of (and/or } \\
\text { impaired } \\
\text { function of) } \\
\text { CD4 }^{+} \text {CD25+ } \\
\text { FOXP3 }^{+} \\
\text {regulatory }{ }^{+} \\
\text {cells }\end{array}$ & Normal & $\begin{array}{l}\text { Elevated } \\
\lg A, \lg E\end{array}$ & $\begin{array}{l}\text { Autoimmune enteropathy, } \\
\text { early onset diabetes, } \\
\text { thyroiditis hemolytic anemia, } \\
\text { thrombocytopenia, eczema }\end{array}$ & $X L$ & $\begin{array}{l}\text { Mutations in } F O X P 3 \text {, } \\
\text { encoding a T cell transcription } \\
\text { factor }\end{array}$ & 304790 \\
\hline $\begin{array}{l}\text { (d) } \mathrm{CD} 25 \\
\text { deficiency }\end{array}$ & $\begin{array}{l}\text { Normal to } \\
\text { modestly } \\
\text { decreased }\end{array}$ & Normal & Normal & $\begin{array}{l}\text { Lymphoproliferation, } \\
\text { autoimmunity. Impaired T cell } \\
\text { proliferation }\end{array}$ & AR & Mutations in IL-2R $\alpha$ chain & 606367 \\
\hline $\begin{array}{l}\text { (e) ITCH } \\
\text { deficiency* }\end{array}$ & $\begin{array}{l}\text { Not assessed } \\
\text { (Th2 skewing in } \\
\text { ltch-deficient } \\
\text { mice) }\end{array}$ & $\begin{array}{l}\text { Not } \\
\text { assessed (B } \\
\text { cells are } \\
\text { dysfunctional } \\
\text { in } \\
\text { Itch-deficient } \\
\text { mice) }\end{array}$ & $\begin{array}{l}\text { Not } \\
\text { assessed } \\
\text { (elevated in } \\
\text { Itch- } \\
\text { deficient } \\
\text { mice) }\end{array}$ & $\begin{array}{l}\text { Multi-organ autoimmunity, } \\
\text { chronic lung disease, failure } \\
\text { to thrive, developmental } \\
\text { delay, macrocephaly }\end{array}$ & $A R$ & $\begin{array}{l}\text { Mutations in } / T C H \text {, an E3 } \\
\text { ubiquitin ligase }\end{array}$ & 613385 \\
\hline
\end{tabular}

$X L, X$-linked inheritance; $A R$, autosomal recessive inheritance; $A D$, autosomal dominant inheritance; DN, double negative; SL, systemic lupus erythematosus.

*Ten or fewer unrelated cases reported in the literature.

STXBP2/Munc18-2 deficiency has been added as the cause of "FHL5," a new form of FHL. Of note, "FHL1" has not yet received a genetic/molecular identification. FADD deficiency is classified among the causes of ALPS. It should be stressed however that FADD deficiency is a more complex syndrome that encompasses

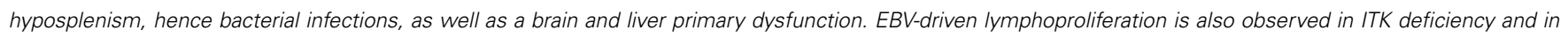
MAGT1 deficiency (Table 1). 
Table 5 | Congenital defects of phagocyte number, function, or both.

\begin{tabular}{|c|c|c|c|c|c|c|}
\hline Disease & $\begin{array}{l}\text { Affected } \\
\text { cells }\end{array}$ & $\begin{array}{l}\text { Affected } \\
\text { function }\end{array}$ & $\begin{array}{l}\text { Associated } \\
\text { features }\end{array}$ & Inheritance & $\begin{array}{l}\text { Genetic } \\
\text { defect/presumed } \\
\text { pathogenesis }\end{array}$ & $\begin{array}{l}\text { OMIM } \\
\text { number }\end{array}$ \\
\hline $\begin{array}{l}\text { (a) Severe } \\
\text { congenital } \\
\text { neutropenia1 } \\
\text { (ELANE } \\
\text { deficiency) }\end{array}$ & $\mathrm{N}$ & $\begin{array}{l}\text { Myeloid } \\
\text { differentiation }\end{array}$ & $\begin{array}{l}\text { Subgroup with } \\
\text { myelodysplasia }\end{array}$ & $A D$ & $\begin{array}{l}\text { ELANE: misfolded protein } \\
\text { response }\end{array}$ & 202700 \\
\hline $\begin{array}{l}\text { (b) SCN2* (GFI } 1 \\
\text { deficiency) }\end{array}$ & N & $\begin{array}{l}\text { Myeloid } \\
\text { differentiation }\end{array}$ & B/T lymphopenia & $A D$ & $\begin{array}{l}\text { GF/1: loss of repression of } \\
\text { ELANE }\end{array}$ & 613107 \\
\hline $\begin{array}{l}\text { (c) } \mathrm{SCN} 3 \\
\text { (Kostmann } \\
\text { disease) }\end{array}$ & $\mathrm{N}$ & $\begin{array}{l}\text { Myeloid } \\
\text { differentiation }\end{array}$ & $\begin{array}{l}\text { Cognitive and neurological } \\
\text { defects in some patients }\end{array}$ & AR & HAX 1:control of apoptosis & 610738 \\
\hline $\begin{array}{l}\text { (e) Glycogen } \\
\text { storage disease } \\
\text { type } 1 \mathrm{~b}\end{array}$ & $N+M$ & $\begin{array}{l}\text { Myeloid } \\
\text { differentiation, } \\
\text { chemotaxis, } \\
\mathrm{O}_{2}^{-} \text {production }\end{array}$ & $\begin{array}{l}\text { Fasting hypoglycemia, lactic } \\
\text { acidosis, hyperlipidemia, } \\
\text { hepatomegaly }\end{array}$ & AR & $\begin{array}{l}\text { G6PT1: glucose-6-phosphate } \\
\text { transporter } 1\end{array}$ & 232220 \\
\hline $\begin{array}{l}\text { (i) Barth } \\
\text { syndrome }\end{array}$ & $\mathrm{N}$ & $\begin{array}{l}\text { Myeloid } \\
\text { differentiation }\end{array}$ & $\begin{array}{l}\text { Cardiomyopathy, growth } \\
\text { retardation }\end{array}$ & $X L$ & $\begin{array}{l}\text { Tafazzin (TAZ) gene: abnormal } \\
\text { lipid structure of } \\
\text { mitochondrial membrane }\end{array}$ & 302060 \\
\hline $\begin{array}{l}\text { (j) Cohen } \\
\text { syndrome }\end{array}$ & $\mathrm{N}$ & $\begin{array}{l}\text { Myeloid } \\
\text { differentiation }\end{array}$ & $\begin{array}{l}\text { Retinopathy, developmental } \\
\text { delay, facial dysmorphisms }\end{array}$ & $A R$ & $\begin{array}{l}\mathrm{COH} 1 \text { gene: Pathogenesis } \\
\text { unknown }\end{array}$ & 216550 \\
\hline $\begin{array}{l}\text { (k) Poikiloderma } \\
\text { with neutropenia }\end{array}$ & $\mathrm{N}$ & $\begin{array}{l}\text { Myeloid } \\
\text { differentiation, } \\
\mathrm{O}_{2}^{-} \text {production }\end{array}$ & Poikiloderma, MDS & $A R$ & C16orf57 gene: Pg unknown & 604173 \\
\hline \multicolumn{7}{|c|}{ 2. Defects of motility } \\
\hline $\begin{array}{l}\text { (a) Leukocyte } \\
\text { adhesion } \\
\text { deficiency type } 1 \\
\text { (LAD1) }\end{array}$ & $\begin{array}{l}\mathrm{N}+\mathrm{M}+ \\
\mathrm{L}+\mathrm{NK}\end{array}$ & $\begin{array}{l}\text { Adherence, } \\
\text { chemotaxis, } \\
\text { endocytosis, } \\
\text { T/NK } \\
\text { cytotoxicity }\end{array}$ & $\begin{array}{l}\text { Delayed cord separation, skin } \\
\text { ulcers periodontitis } \\
\text { leukocytosis }\end{array}$ & AR & $\begin{array}{l}\text { INTGB2: adhesion protein } \\
\text { (CD18) }\end{array}$ & 116920 \\
\hline
\end{tabular}


Table 5 | Continued

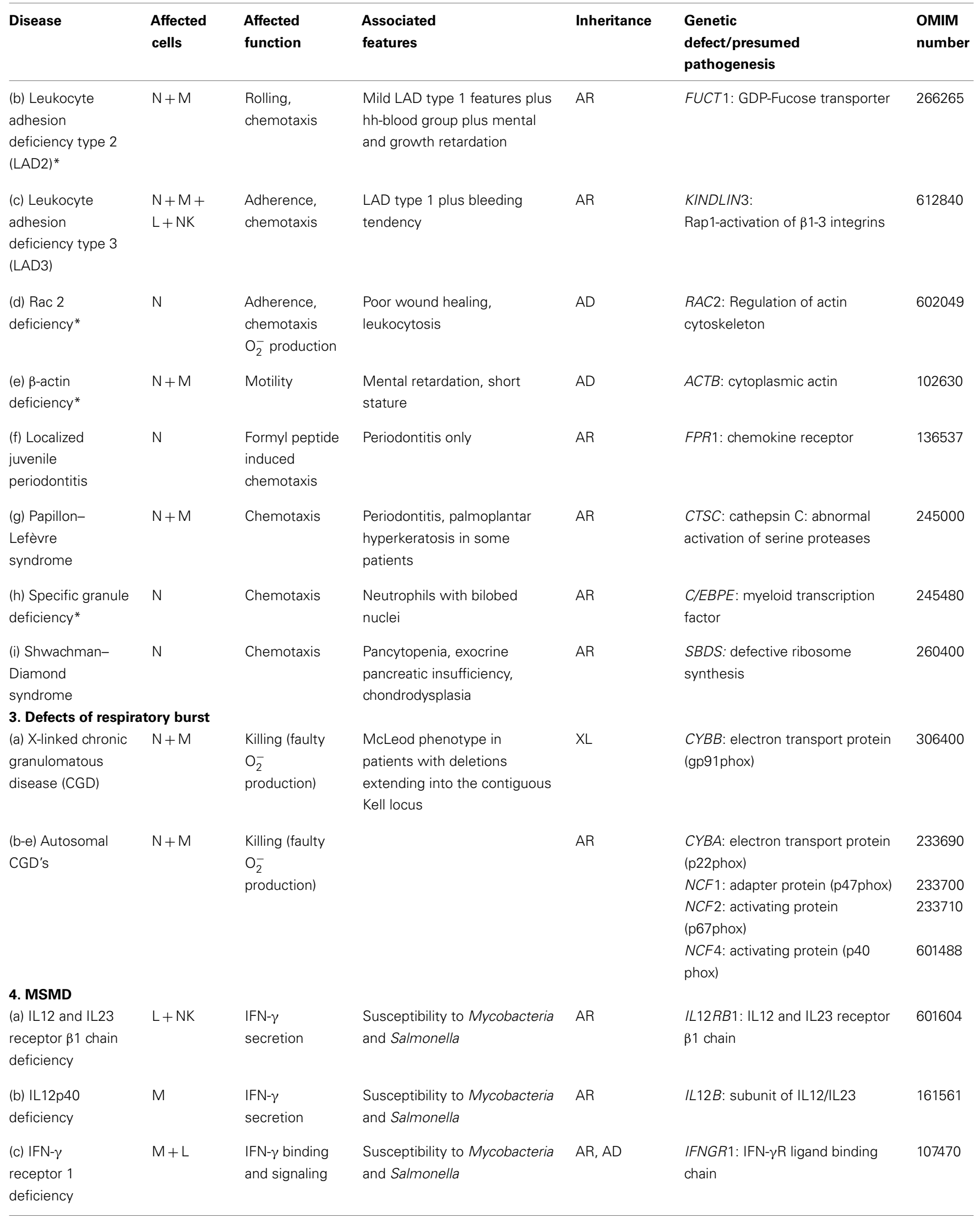


Table 5 | Continued

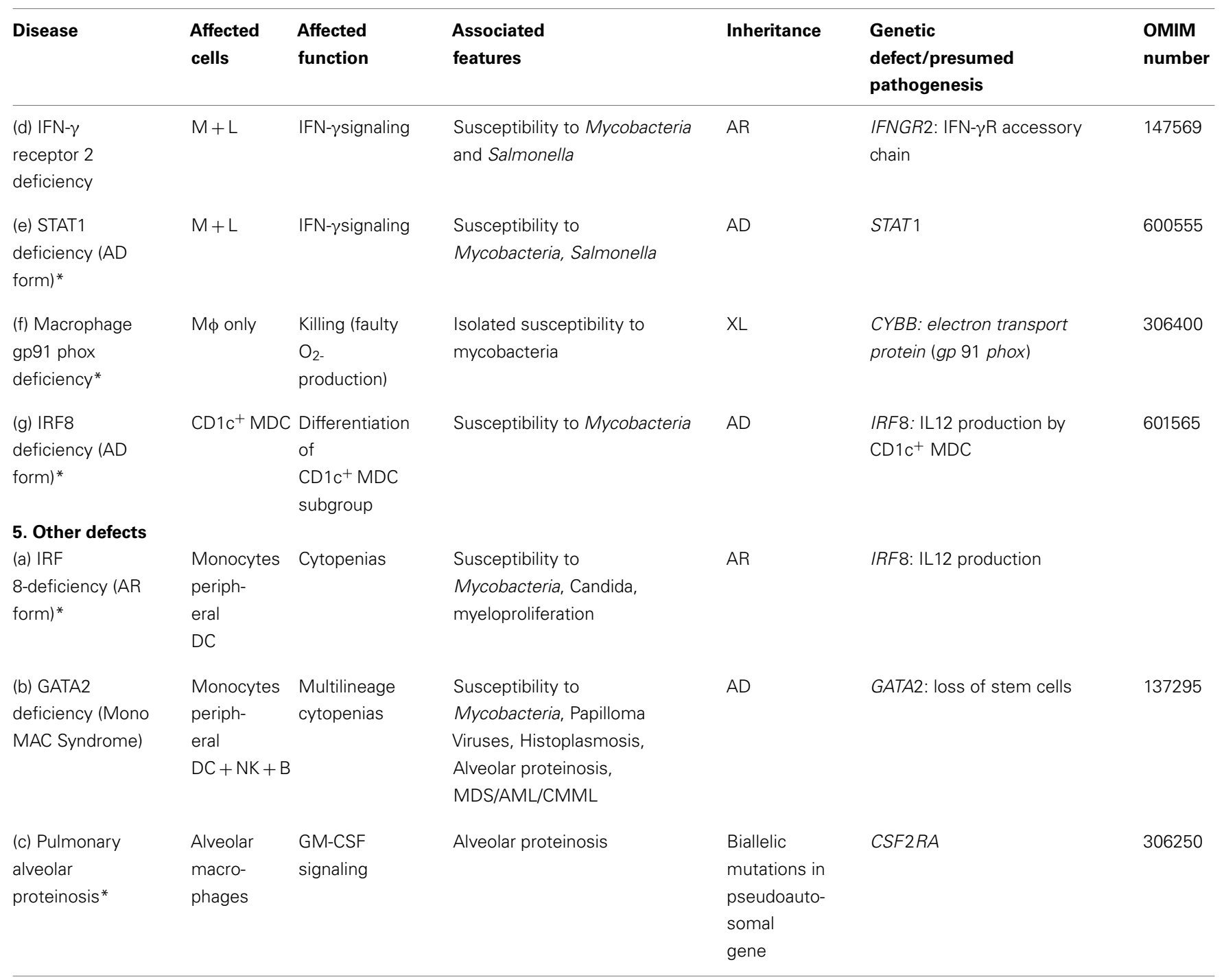

$X L, X$-linked inheritance; $A R$, autosomal recessive inheritance; $A D$, autosomal dominant inheritance; $A C T B$, actin beta; $B, B$-lymphocytes; CEBPE, CCAAT/enhancerbinding protein epsilon; CMML, chronic myelomonocytic leukaemia; CTSC, cathepsin $C$; CYBA, cytochrome b alpha subunit; CYBB, cytochrome b beta subunit; $D C$, dendritic cells; ELANE, elastase neutrophil-expressed; GATA2, GATA binding protein 2; IFN, interferon; IFNGR1, interferon-gamma receptor subunit 1; IFNGR2, interferon-gamma receptor subunit 2; IL12B, interleukin-12 beta subunit; IL12RB1, interleukin-12 receptor beta 1; IFR8, interferon regulatory factor 8; F, fibroblasts; FPR1, formyl peptide receptor 1; FUCT1, fucose transporter 1; GFI1, growth factor independent 1; HAX1, HLCS1-associated protein X1; ITGB2, integrin beta-2; L, lymphocytes; M, monocytes-macrophages; MDC, myeloid dendritic cells; MDS, myelodysplasia; Mel, melanocytes; M申, macrophages; MSMD, Mendelian susceptibility to mycobacterial disease; N, neutrophils; NCF1, neutrophil cytosolic factor 1; NCF2, neutrophil cytosolic factor 2; NCF4, neutrophil cytosolic factor 4; NK, natural killer cells; ROBLD3, roadblock domain containing 3; SBDS, Shwachman-Bodian-Diamond syndrome; STAT, signal transducer and activator of transcription.

*Ten or fewer unrelated cases reported in the literature.

Table 5 includes seven newly described genetic defects of phagocyte number and/or function including Barth syndrome, Cohen syndrome and Poikiloderma with neutropenia. In these three clinically well-known diseases the genetic defects have been elucidated, although their molecular pathogenesis remains ill-defined. A new cause of autosomal recessive chronic granulomatous disease, namely a deficiency of the cytosolic activating protein p40 phox, has now been found in two CGD patients and is included under defects of respiratory burst. Under the heading of Mendelian susceptibility of mycobacterial disease (MSMD) two new entities were added: a) a subgroup of X-linked gp91 phox deficiency with isolated susceptibility to mycobacteria and a defect of the respiratory burst in macrophages only; b) an autosomal dominant form of IRF8 deficiency, resulting from a lack of $C D 1 C^{+}$myeloid dendritic cells that would normally secrete IL 12. The clinical phenotype of MSMD may vary, depending on the nature of the genetic defect. Finally GATA2 deficiency was recently identified as the cause of the Mono MAC syndrome, with multilineage cytopenias (of monocytes, peripheral dendritic cells, NK- and B-lymphocytes) resulting in opportunistic infections (including mycobacteria), alveolar proteinosis and malignancy. 
Table 6 | Defects in innate immunity.

\begin{tabular}{|c|c|c|c|c|c|c|}
\hline Disease & Affected cell & $\begin{array}{l}\text { Functional } \\
\text { defect }\end{array}$ & Associated features & Inheritance & $\begin{array}{l}\text { Genetic defect/presumed } \\
\text { pathogenesis }\end{array}$ & $\begin{array}{l}\text { OMIM } \\
\text { number }\end{array}$ \\
\hline \multicolumn{7}{|c|}{ 1. Anhidrotic ectodermal dysplasia with immunodeficiency (EDA-ID) } \\
\hline $\begin{array}{l}\text { (b) EDA-ID, } \\
\text { autosomal } \\
\text { dominant* }\end{array}$ & $\begin{array}{l}\text { Lymphocytes + } \\
\text { monocytes }\end{array}$ & $\begin{array}{l}\text { NFKB signaling } \\
\text { pathway }\end{array}$ & $\begin{array}{l}\text { Anhidrotic ectodermal } \\
\text { dysplasia }+T \text { cell } \\
\text { defect + various infections }\end{array}$ & $A D$ & $\begin{array}{l}\text { Gain-of-function mutation of } \\
I K B A \text {, resulting in impaired } \\
\text { activation of NF-kB }\end{array}$ & 612132 \\
\hline $\begin{array}{l}\text { 3. MyD88 } \\
\text { deficiency }\end{array}$ & $\begin{array}{l}\text { Lymphocytes + } \\
\text { monocytes }\end{array}$ & $\begin{array}{l}\text { TIR-MyD88 } \\
\text { signaling pathway }\end{array}$ & $\begin{array}{l}\text { Bacterial infections } \\
\text { (pyogenes) }\end{array}$ & AR & $\begin{array}{l}\text { Mutation of MYD88, a } \\
\text { component of the TLR and } \\
\text { IL-1R-signaling pathway }\end{array}$ & 612260 \\
\hline $\begin{array}{l}\text { 4. WHIM } \\
\text { (warts, } \\
\text { hypogamma- } \\
\text { globulinemia, } \\
\text { infections, } \\
\text { myelokathexis) } \\
\text { syndrome }\end{array}$ & $\begin{array}{l}\text { Granulocytes + } \\
\text { lymphocytes }\end{array}$ & $\begin{array}{l}\text { Increased } \\
\text { response of the } \\
\text { CXCR4 } \\
\text { chemokine } \\
\text { receptor to its } \\
\text { ligand CXCL12 } \\
\text { (SDF-1) }\end{array}$ & $\begin{array}{l}\text { Hypogammaglobulinemia, } \\
\text { reduced B cell number, } \\
\text { severe reduction of neutrophil } \\
\text { count, warts/HPV infection }\end{array}$ & $A D$ & $\begin{array}{l}\text { Gain-of-function mutations of } \\
\text { CXCR4, the receptor for } \\
\text { CXCL12 }\end{array}$ & 193670 \\
\hline $\begin{array}{l}\text { 5. Epidermo- } \\
\text { dysplasia } \\
\text { verruciformis }\end{array}$ & $\begin{array}{l}\text { Keratinocytes and } \\
\text { leukocytes }\end{array}$ & & $\begin{array}{l}\text { Human Papilloma virus (group } \\
\text { B1) infections and cancer of } \\
\text { the skin }\end{array}$ & $A R$ & Mutations of EVER1, EVER2 & 226400 \\
\hline $\begin{array}{l}\text { (b) UNC93B1 } \\
\text { deficiency }\end{array}$ & $\begin{array}{l}\text { CNS resident } \\
\text { cells and } \\
\text { fibroblasts }\end{array}$ & $\begin{array}{l}\text { UNC-93B- } \\
\text { dependent IFN- } \alpha \text {, } \\
-\beta \text {, and }-\lambda \\
\text { induction }\end{array}$ & $\begin{array}{l}\text { Herpes simplex virus } 1 \\
\text { encephalitis }\end{array}$ & AR & Mutations of UNC93B1 & 610551 \\
\hline $\begin{array}{l}\text { (c) TRAF3 } \\
\text { deficiency }\end{array}$ & $\begin{array}{l}\text { CNS resident } \\
\text { cells and } \\
\text { fibroblasts }\end{array}$ & $\begin{array}{l}\text { TRAF3-dependent } \\
\text { IFN- } \alpha,-\beta \text {, and }-\lambda \\
\text { induction }\end{array}$ & $\begin{array}{l}\text { Herpes simplex virus } 1 \\
\text { encephalitis }\end{array}$ & $A D$ & Mutation of TRAF3 & \\
\hline $\begin{array}{l}\text { 7. Predisposi- } \\
\text { tion to fungal } \\
\text { diseases* }\end{array}$ & $\begin{array}{l}\text { Mononuclear } \\
\text { phagocytes }\end{array}$ & $\begin{array}{l}\text { CARD9 signaling } \\
\text { pathway }\end{array}$ & $\begin{array}{l}\text { Invasive candidiasis and } \\
\text { peripheral dermatophytosis }\end{array}$ & AR & Mutations of CARD9 & 212050 \\
\hline \multicolumn{7}{|c|}{ 8. Chronic mucocutaneous candidiasis (CMC) } \\
\hline $\begin{array}{l}\text { (a) IL-17RA } \\
\text { deficiency* }\end{array}$ & $\begin{array}{l}\text { Epithelial cells, } \\
\text { fibroblasts, } \\
\text { mononuclear } \\
\text { phagocytes }\end{array}$ & $\begin{array}{l}\text { IL-17RA signaling } \\
\text { pathway }\end{array}$ & $\mathrm{CMC}$ & AR & Mutation in IL-17RA & 605461 \\
\hline $\begin{array}{l}\text { (b) IL-17F } \\
\text { deficiency* }\end{array}$ & T cells & $\begin{array}{l}\text { IL-17F-containing } \\
\text { dimers }\end{array}$ & $\mathrm{CMC}$ & $A D$ & Mutation in $I L-17 F$ & 606496 \\
\hline
\end{tabular}


Table 6 | Continued

\begin{tabular}{|c|c|c|c|c|c|c|}
\hline Disease & Affected cell & $\begin{array}{l}\text { Functional } \\
\text { defect }\end{array}$ & Associated features & Inheritance & $\begin{array}{l}\text { Genetic defect/presumed } \\
\text { pathogenesis }\end{array}$ & $\begin{array}{l}\text { OMIM } \\
\text { number }\end{array}$ \\
\hline $\begin{array}{l}\text { (c) STAT1 gain- } \\
\text { of-function }\end{array}$ & T cells & $\begin{array}{l}\text { Gain-of-function } \\
\text { STAT1 mutations } \\
\text { that impair the } \\
\text { development of } \\
\text { IL-17-producing T } \\
\text { cells }\end{array}$ & $\mathrm{CMC}$ & $A D$ & Mutations in STAT1 & 614162 \\
\hline $\begin{array}{l}\text { 9. Trypanoso- } \\
\text { miasis* }\end{array}$ & & APOLI & Trypanosomiasis & $A D$ & Mutation in APOL-I & 603743 \\
\hline
\end{tabular}

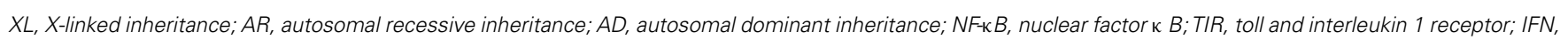
interferon; HP, human papilloma virus; TLR, toll-like receptor; IL: interleukin.

*Ten or fewer unrelated cases reported in the literature.

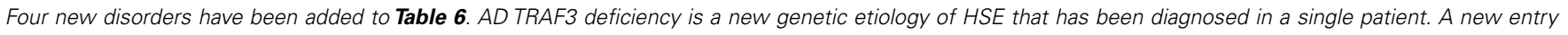

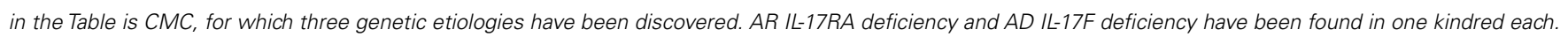

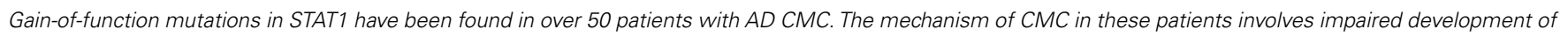
IL-17-producing T cells, due to the hyperactivity of STAT1-dependent signals.

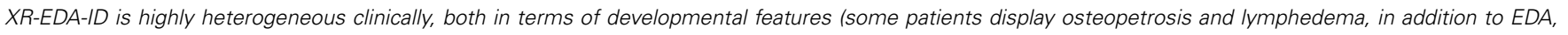

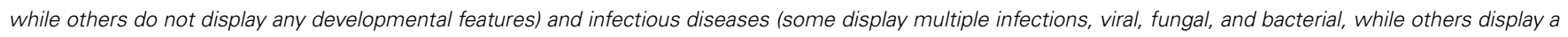
single type of infection). The various OMIM entries correspond to these distinct clinical diseases. 
Table 7 | Autoinflammatory disorders.

Disease Affected cells $\quad \begin{aligned} & \text { Functional } \\ & \text { defects }\end{aligned}$

\section{Defects effecting the inflammasome}

(a) Familial
Mediterranean
(b) Hyper lgD
syndrome

(c) Muckle-Wells

syndrome

(d) Familial cold

autoinflammatory

syndrome

\begin{abstract}
(e) Neonatal onset
multisystem

inflammatory

disease (NOMID) or

chronic infantile

neurologic

cutaneous and

articular syndrome

(CINCA)
\end{abstract}

\section{Non-inflammasome-related conditions}

\section{(a) TNF \\ receptor-associated \\ periodic syndrome \\ (TRAPS)}

(b) Early onset
inflammatory bowel
disease

(c) Pyogenic sterile arthritis, pyoderma gangrenosum, acne (PAPA) syndrome
Mature

granulocytes,

cytokine-

activated

monocytes

PMNs

monocytes

PMNs,

monocytes

PMNs,

same as above

chondrocytes

PMNs,

monocytes

Mutations of 55-kD TNF

receptor leading to

intracellular receptor retention or diminished soluble cytokine receptor available to bind TNF

Monocyte/ macrophage, activated $\mathrm{T}$ cells

Hematopoietic tissues, upregulated in activated T cells
Mutation in IL-10 or IL-10
Associated

Features
Inheritance Genetic defect/

presumed

pathogenesis
OMIM

number

namer

Recurrent fever, serositis

and inflammation

$A R$

Mutations of MEFV

responsive to colchicine.

Predisposes to vasculitis

and inflammatory bowel

disease

Periodic fever and

AR

Mutations of

MVK

levels

Urticaria, SNHL,

amyloidosis

AD

Mutations of

191900

CIAS1 (also called

PYPAF1 or

$N A L P 3)$

Non-pruritic urticaria,

arthritis, chills, fever, and

leukocytosis after cold

exposure

Neonatal onset rash,

chronic meningitis, and

arthropathy with fever and

inflammation

Recurrent fever, serositis,

AD

Mutations of

TNFRSF1A
Mutations of

CIAS1 Mutations

of NLRP12

Mutations of

CIAS1
249100

(249100

142680 inflammation receptor leads to increase of TNF $\gamma$ and other proinflammatory cytokines

Early onset enterocolitis enteric fistulas, perianal abscesses, chronic

folliculitis

Destructive arthritis, inflammatory skin rash, myositis

146933

IL10, IL10RA, or

\section{Disordered actin}

reorganization leading to

compromised physiologic

signaling during inflammatory

response
Mutations in IL10RB

AR

$A D$

Mutations of PSTPIP1 (also called C2BP1) 
Table 7 | Continued

\begin{tabular}{|c|c|c|c|c|c|c|}
\hline Disease & Affected cells & $\begin{array}{l}\text { Functional } \\
\text { defects }\end{array}$ & $\begin{array}{l}\text { Associated } \\
\text { Features }\end{array}$ & Inheritance & $\begin{array}{l}\text { Genetic defect/ } \\
\text { presumed } \\
\text { pathogenesis }\end{array}$ & $\begin{array}{l}\text { OMIM } \\
\text { number }\end{array}$ \\
\hline $\begin{array}{l}\text { (e) Chronic recurrent } \\
\text { multifocal } \\
\text { osteomyelitis and } \\
\text { congenital } \\
\text { dyserythropoietic } \\
\text { anemia (Majeed } \\
\text { syndrome)* }\end{array}$ & $\begin{array}{l}\text { Neutrophils, } \\
\text { bone marrow } \\
\text { cells }\end{array}$ & Undefined & $\begin{array}{l}\text { Chronic recurrent } \\
\text { multifocal osteomyelitis, } \\
\text { transfusion-dependent } \\
\text { anemia, cutaneous } \\
\text { inflammatory disorders }\end{array}$ & $A R$ & $\begin{array}{l}\text { Mutations of } \\
\text { LPIN2 }\end{array}$ & 609628 \\
\hline $\begin{array}{l}\text { (f) DIRA (Deficiency } \\
\text { of the interleukin } 1 \\
\text { receptor } \\
\text { antagonist)* }\end{array}$ & $\begin{array}{l}\text { PMNs, } \\
\text { monocytes }\end{array}$ & $\begin{array}{l}\text { Mutations in the IL1 receptor } \\
\text { antagonist allows unopposed } \\
\text { action of interleukin } 1\end{array}$ & $\begin{array}{l}\text { Neonatal onset of sterile } \\
\text { multifocal osteomyelitis, } \\
\text { periostitis, and pustulosis }\end{array}$ & $A R$ & $\begin{array}{l}\text { Mutations of } \\
\text { IL1RN }\end{array}$ & 612852 \\
\hline
\end{tabular}

$A R$, autosomal recessive inheritance; $A D$, autosomal dominant inheritance; $P M N$, polymorphonuclear cells; ASC, apoptosis-associated speck-like protein with a caspase recruitment domain; CARD, caspase recruitment domain; CD2BP1, CD2 binding protein 1; PSTPIP1, proline/serine/threonine phosphatase-interacting protein 1; SNHL, sensorineural hearing loss; CIAS1, cold-induced autoinflammatory syndrome 1.

*Ten or fewer unrelated cases reported in the literature.

Autoinflammatory diseases are clinical disorders marked by abnormally increased inflammation, mediated predominantly by the cells and molecules of the innate immune system, with a significant host predisposition. While the genetic defect of one of the most common autoinflammatory conditions, PFAPA, is not known, recent studies suggest that it is associated with activation of IL-1 pathway and response to IL-1 beta antagonists.

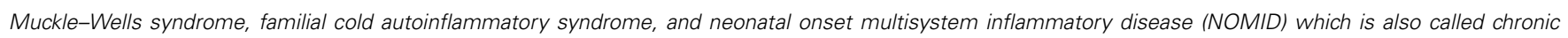

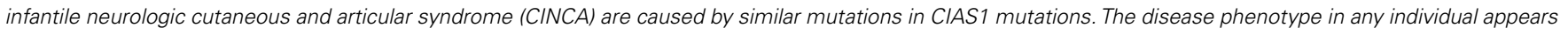
to depend on modifying effects of other genes and environmental factors. 
Table 8 | Complement deficiencies.

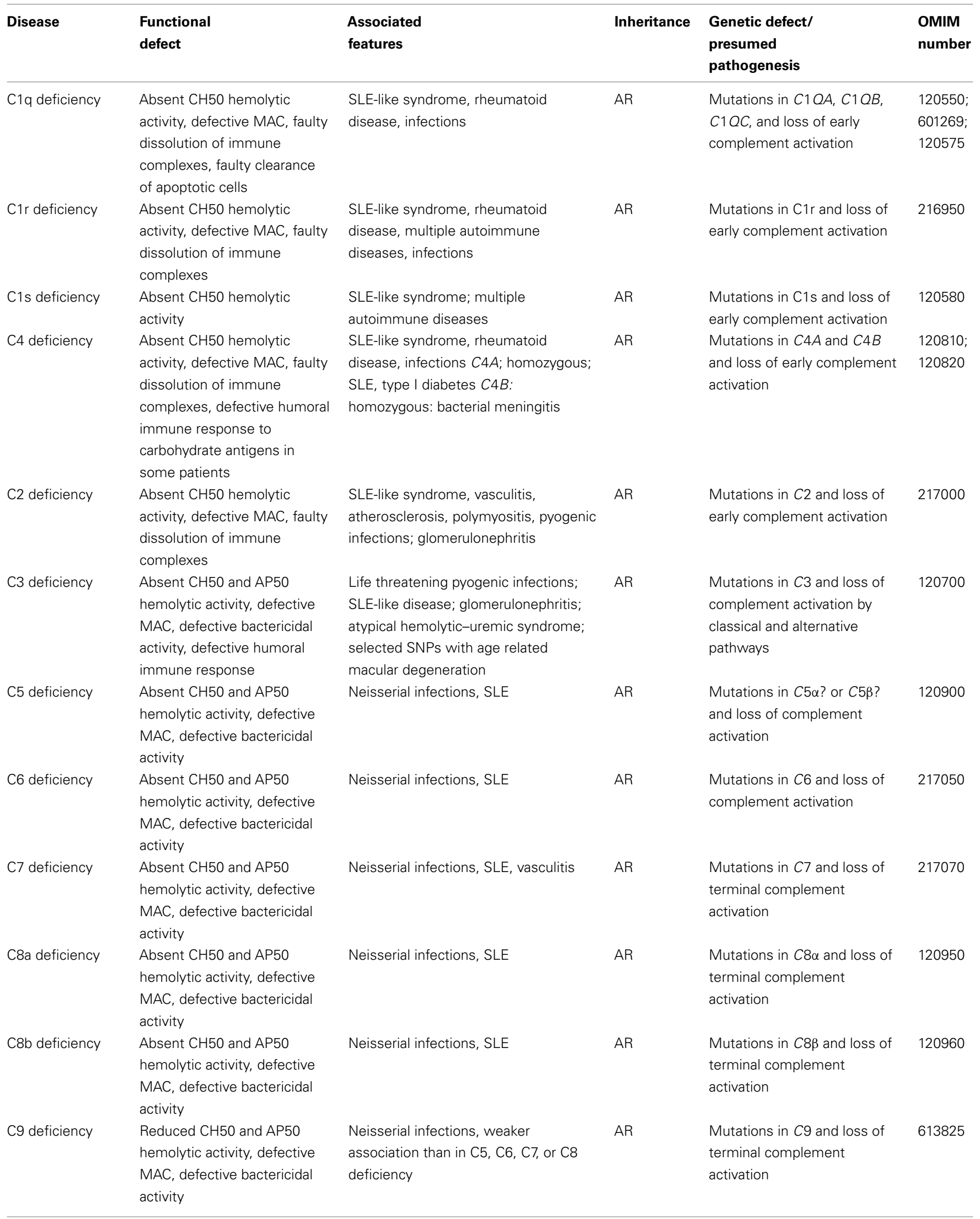


Table 8 | Continued

\begin{tabular}{|c|c|c|c|c|c|}
\hline Disease & $\begin{array}{l}\text { Functional } \\
\text { defect }\end{array}$ & $\begin{array}{l}\text { Associated } \\
\text { features }\end{array}$ & Inheritance & $\begin{array}{l}\text { Genetic defect/ } \\
\text { presumed } \\
\text { pathogenesis }\end{array}$ & $\begin{array}{l}\text { OMIM } \\
\text { number }\end{array}$ \\
\hline $\begin{array}{l}\text { Factor D } \\
\text { deficiency }\end{array}$ & $\begin{array}{l}\text { Absent AP50 hemolytic } \\
\text { activity }\end{array}$ & Severe neisserial infection & $A R$ & $\begin{array}{l}\text { Mutations in factor D (CFD), } \\
\text { impairing alternative } \\
\text { complement activation }\end{array}$ & 134350 \\
\hline $\begin{array}{l}\text { Factor I } \\
\text { deficiency }\end{array}$ & $\begin{array}{l}\text { Spontaneous activation of the } \\
\text { alternative complement } \\
\text { pathway with consumption of } \\
\text { C3 }\end{array}$ & $\begin{array}{l}\text { Recurrent pyogenic infections, } \\
\text { glomerulonephritis, SLE; } \\
\text { hemolytic-uremic syndrome; selected } \\
\text { SNPS: severe pre-eclampsia }\end{array}$ & $A R$ & $\begin{array}{l}\text { Mutations in factor } \mathrm{I}(\mathrm{CF} /) \text {, } \\
\text { leading to accelerated } \\
\text { catabolism of } \mathrm{C} 3\end{array}$ & 610984 \\
\hline $\begin{array}{l}\text { Factor } \mathrm{H} \\
\text { deficiency }\end{array}$ & $\begin{array}{l}\text { Spontaneous activation of the } \\
\text { alternative complement } \\
\text { pathway with consumption of } \\
\text { C3 }\end{array}$ & $\begin{array}{l}\text { Hemolytic-uremic syndrome, } \\
\text { membranoproliferative } \\
\text { glomerulonephritis; neisserial } \\
\text { infections; selected SNPS: severe } \\
\text { pre-eclampsia }\end{array}$ & $A R$ & $\begin{array}{l}\text { Mutations in factor } \mathrm{H}(\mathrm{CFH}) \text {, } \\
\text { leading to continuous } \\
\text { activation of the alternative } \\
\text { complement pathway and } \mathrm{C} 3 \\
\text { deposition in tissues }\end{array}$ & 609814 \\
\hline $\begin{array}{l}\text { MASP1 } \\
\text { deficiency }\end{array}$ & $\begin{array}{l}\text { Potential loss of embryonic } \\
\text { cell migration signals }\end{array}$ & $\begin{array}{l}\text { A developmental syndrome of facial } \\
\text { dysmorphism, cleft lip, and/or palate, } \\
\text { craniosynostosis, learning disability } \\
\text { and genital, limb and vesicorenal } \\
\text { anomalies }\end{array}$ & $A R$ & $\begin{array}{l}\text { Mutations in MASP1 leading } \\
\text { to impaired complement } \\
\text { pathway through the } \\
\text { mannan-binding lectin serine } \\
\text { proteases }\end{array}$ & 600521 \\
\hline $\begin{array}{l}\text { MASP2 } \\
\text { deficiency* }\end{array}$ & $\begin{array}{l}\text { Absent hemolytic activity by } \\
\text { the lectin pathway }\end{array}$ & $\begin{array}{l}\text { Pyogenic infections; inflammatory lung } \\
\text { disease }\end{array}$ & $A R$ & $\begin{array}{l}\text { Mutations in } M A S P 2 \text { leading } \\
\text { to impaired complement } \\
\text { pathway through the } \\
\text { mannan-binding lectin serine } \\
\text { proteases }\end{array}$ & 605102 \\
\hline $\begin{array}{l}\text { Complement } \\
\text { receptor } 3 \text { (CR3) } \\
\text { deficiency }\end{array}$ & See LAD1 in Table 5 & & $A R$ & Mutations in INTGB2 & 116920 \\
\hline $\begin{array}{l}\text { Membrane } \\
\text { cofactor protein } \\
\text { (CD46) deficiency }\end{array}$ & $\begin{array}{l}\text { Inhibitor of complement } \\
\text { alternate pathway, decreased } \\
\text { C3b binding }\end{array}$ & $\begin{array}{l}\text { Glomerulonephritis, atypical } \\
\text { hemolytic-uremic syndrome; selected } \\
\text { SNPS: severe pre-eclampsia }\end{array}$ & $A D$ & $\begin{array}{l}\text { Mutations in } M C P \text { leading to } \\
\text { loss of the cofactor activity } \\
\text { needed for the factor } \\
\text { I-dependent cleavage of C3B } \\
\text { and C4B }\end{array}$ & 120920 \\
\hline $\begin{array}{l}\text { Membrane attack } \\
\text { complex inhibitor } \\
\text { (CD59) deficiency }\end{array}$ & $\begin{array}{l}\text { Erythrocytes highly } \\
\text { susceptible to } \\
\text { complement-mediated lysis }\end{array}$ & Hemolytic anemia, thrombosis & $A R$ & $\begin{array}{l}\text { Mutations in CD59 leading to } \\
\text { loss of this membrane } \\
\text { inhibitor of the membrane } \\
\text { attack complexes }\end{array}$ & 107271 \\
\hline
\end{tabular}


Table 8 | Continued

\begin{tabular}{|c|c|c|c|c|c|}
\hline Disease & $\begin{array}{l}\text { Functional } \\
\text { defect }\end{array}$ & $\begin{array}{l}\text { Associated } \\
\text { features }\end{array}$ & Inheritance & $\begin{array}{l}\text { Genetic defect/ } \\
\text { presumed } \\
\text { pathogenesis }\end{array}$ & $\begin{array}{l}\text { OMIM } \\
\text { number }\end{array}$ \\
\hline $\begin{array}{l}\text { Paroxysmal } \\
\text { nocturnal } \\
\text { hemoglobinuria }\end{array}$ & $\begin{array}{l}\text { Complement-mediated } \\
\text { hemolysis }\end{array}$ & $\begin{array}{l}\text { Recurrent hemolysis; hemoglobinuria, } \\
\text { abdominal pain, smooth muscle } \\
\text { dystonias, fatigue, and thrombosis }\end{array}$ & $\begin{array}{l}\text { Acquired } \\
\text { X-linked } \\
\text { mutation }\end{array}$ & $\begin{array}{l}\text { Disease results from the } \\
\text { expansion of hematopoietic } \\
\text { stem cells bearing mutations } \\
\text { in PIGA and subsequent loss } \\
\text { of biosynthesis of } \\
\text { glycosylphosphatidylinositol } \\
\text { (GPI) a moiety that attaches } \\
\text { proteins to the cell surface. }\end{array}$ & 300818 \\
\hline $\begin{array}{l}\text { Immunodeficiency } \\
\text { associated with } \\
\text { Ficolin } 3 \\
\text { deficiency* }\end{array}$ & $\begin{array}{l}\text { Absence of complement } \\
\text { activation by the Ficolin } 3 \\
\text { pathway. }\end{array}$ & $\begin{array}{l}\text { Recurrent severe pyogenic infections } \\
\text { mainly in the lungs; necrotizing } \\
\text { enterocolitis in infancy; selective } \\
\text { antibody defect to pneumococcal } \\
\text { polysaccharides }\end{array}$ & $A R$ & $\begin{array}{l}\text { Mutations in FCN3, leading to } \\
\text { impaired complement } \\
\text { deposition }\end{array}$ & 604973 \\
\hline
\end{tabular}

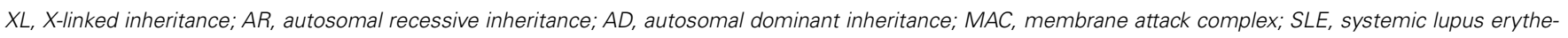
matosus; MBP, Mannose binding Protein; MASP2, MBP associated serine protease 2.

*Ten or fewer unrelated cases reported in the literature.

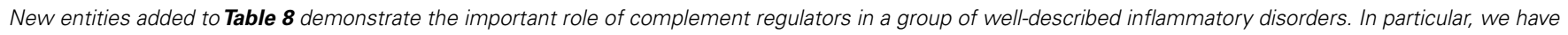

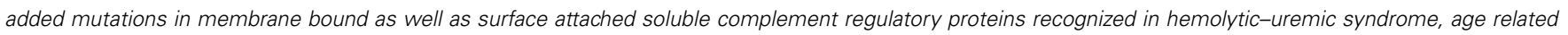

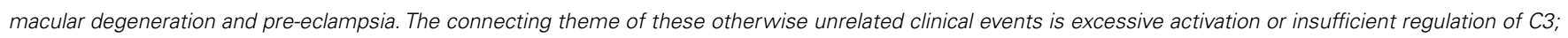

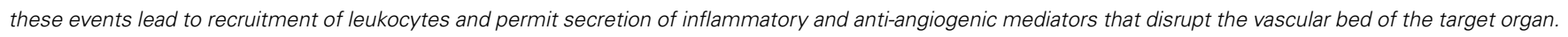

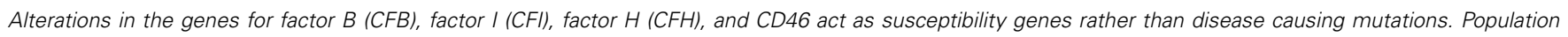

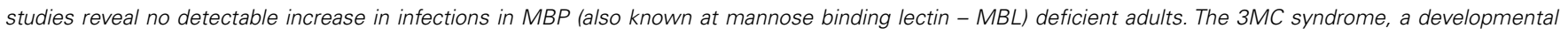
syndrome, has been variously called Carnevale, Mingarelli, Malpuech, and Michels syndrome.

Conflict of Interest Statement: The authors declare that the research was conducted in the absence of any commercial or financial relationships that could be construed as a potential conflict of interest.

Received: 25 August 2011; accepted: 20 September 2011; published online: 08 November 2011.
Citation: Al-Herz W, Bousfiha A, Casanova J-L, Chapel H, Conley ME, Cunningham-Rundles C, Etzioni A, Fischer A, Franco JL, Geha RS, Hammarström L, Nonoyama S, Notarangelo $L D$, Ochs HD, Puck JM, Roifman CM, Seger $R$ and Tang MLK (2011) Primary immunodeficiency diseases: an update on the classification from the International Union of Immunological
Societies Expert Committee for Primary Immunodeficiency. Front. Immun. 2:54. doi: 10.3389/fimmu.2011.00054

This article was submitted to Frontiers in Primary Immunodeficiencies, a specialty of Frontiers in Immunology.

Copyright () 2011 Al-Herz, Bousfiha, Casanova, Chapel, Conley, Cunningham-Rundles, Etzioni, Fischer, Franco, Geha, Hammarström,
Nonoyama, Notarangelo, Ochs, Puck, Roifman, Seger and Tang. This is an open-access article subject to a nonexclusive license between the authors and Frontiers Media SA, which permits use, distribution and reproduction in other forums, provided the original authors and source are credited and other Frontiers conditions are complied with. 